NBER WORKING PAPER SERIES

\title{
DO ENDOWMENTS PREDICT THE LOCATION \\ OF PRODUCTION? EVIDENCE FROM \\ NATIONAL AND INTERNATIONAL DATA
}

\author{
Jeffrey R. Bernstein \\ David E. Weinstein \\ Working Paper 6815 \\ http://www.nber.org/papers/w6815 \\ NATIONAL BUREAU OF ECONOMIC RESEARCH \\ 1050 Massachusetts Avenue \\ Cambridge, MA 02138 \\ November 1998
}

We wish to thank, without implicating, Alan Deardorff, Peter Debaere, James Harrigan, Gary Saxonhouse, Robert Stern, and especially Donald Davis. Matt Fleming provided excellent research assistance. The views expressed here are those of the author and do not reflect those of the National Bureau of Economic Research.

(C) 1998 by Jeffrey R. Bernstein and David E. Weinstein. All rights reserved. Short sections of text, not to exceed two paragraphs, may be quoted without explicit permission provided that full credit, including $(\mathbb{C}$ notice, is given to the source. 
Do Endowments Predict the Location of Production?

Evidence from National and International Data

Jeffrey R. Bernstein and David E. Weinstein

NBER Working Paper No. 6815

November 1998

JEL No. F11, R13

\section{ABSTRACT}

Examining the relationship between factor endowments and production patterns using international and Japanese regional data, we provide the first empirical confirmation of Ethier's correlation approach to the Rybczynski theorem. Moreover, we find evidence of substantial production indeterminacy. Prediction errors are six to thirty times larger for goods traded relatively freely. A compelling explanation of this phenomenon is the existence of more goods than factors in the presence of trade costs. This result implies that regressions of trade or output on endowments have weak theoretical foundations. Furthermore, since errors are largest in data sets where trade costs are small, we explain why the common methodology of imputing trade barriers from regression residuals often leads to backwards results.

Jeffrey R. Bernstein

Harvard University

Morgan Hall 262c

Boston, MA 02163

David E. Weinstein

University of Michigan

Business School

701 Tappan St.

Ann Arbor, MI 48109

and NBER

Weinstei@umich.edu 
In fact, there are exactly 2,118 goods and 2,118

factors. You did know that, didn't you?

Edward Leamer (1984)

\section{Introduction}

Trade economists regularly build models in which the number of goods exceeds, equals, or is less than the number of factors. These seemingly innocuous variations in model structure have profound implications regarding the ability of general-equilibrium models to explain production patterns. In models where the number of goods exceeds the number of factors, output and hence trade flows can no longer be determined solely on the basis of a country's factor endowments. Indeed, it is precisely because of this potential indeterminacy of trade and production that many tests of the factor abundance theory have focused on the Heckscher-Ohlin-Vanek (HOV) model. This formulation posits a relationship between factor endowments and the factor services that are embodied in goods trade. According to the HOV model, countries will export the services of relatively abundant factors and import the services of relatively scarce factors.

Though the HOV model generates precise predictions of trade in factor services, more often economists are interested in using factor endowments to estimate commodity trade flows. This task generally requires the existence of what we call the "factor-endowments-driven" (FED) model of production, which provides the foundation for a common, one-to-one mapping of factor endowments into outputs. ${ }^{1}$ A necessary condition for this relationship to hold is the existence of an equal number of goods and factors. Consequently, the empirical literature has tended to rely implicitly or explicitly upon the "even case" or "square model," i.e., the implausible assumption that there are equal numbers of goods and factors. This assumption has troubled empirical trade economists, even though they often adopted it for convenience. As Leamer and Levinsohn (1995, p. 1363) remark in their survey of the empirical trade literature, "one rather awkward assumption

\footnotetext{
${ }^{1}$ By "common" we mean that the function linking outputs to endowments is the same across all countries and independent of factor endowments.
} 
that cries out for change is that of equal numbers of commodities and factors. After all, we really don't know how to count either."

While we agree that it is not possible to determine the number of goods and factors by counting them, we argue that the observed production patterns are consistent only with a world in which the number of goods exceeds the number of factors. Our claim is predicated on the following empirical prediction. Namely, if there are more goods than factors, then even in cases where the HOV model holds, it should not be possible to predict output on the basis of endowments-i.e., the FED model of production should fail. We implement this test on Japanese prefectural data, analyzing whether factor endowments determine the location of production or whether outputs are indeterminate. Even for this sample of Japanese regions in which the HOV model of production holds, we find that the FED model fails, as indicated by enormous indeterminacy in production patterns. This is the first empirical verification that production indeterminacy arising from the existence of more goods than factors is a major problem for predicting specialization.

Furthermore, we show that the estimated coefficients obtained from regressing output or trade on factor endowments, often called "Rybczynski derivatives," are not linked to the underlying technology in the way required by theory. Therefore they cannot be interpreted as providing information about a structural relationship between output and factor endowments. This means that regressions of output or trade on factor endowments have weak theoretical foundations.

When we use an international data set, surprisingly much of the indeterminacy in the location of production disappears. That is, residuals from regressions of output on factor endowments are far larger for a data set of regions with negligible to low trade costs than for a data set of countries with presumably higher and more ubiquitous costs of trade. We interpret this finding as evidence in support of the hypothesis that trade costs help to render international production patterns determinate. However, the fact that the production patterns appear to be more predictable in the presence of trade costs undermines a major application of regressions of 
trade on factor endowments: attempts to identify trade barriers on the basis of prediction errors from these regressions. Indeed, this phenomenon may explain the puzzle identified by Pritchett (1996), namely the significant negative correlations between conventional measures of protection and the estimated trade barriers derived from regressions of trade on factor endowments.

\section{Background}

The Heckscher-Ohlin-Samuelson model was originally formulated with two factors and two goods. In this simple $2 \times 2$ (two goods, two factors) world, it is easy to derive the major trade theorems (Factor Price Equalization, Rybczynski, Heckscher-Ohlin, and StolperSamuelson). Extensions of this model into multigood, multifactor versions are considerably more complicated, and even in the "square" $\mathrm{N} \times \mathrm{N}$ case, most of the strong results of the $2 \times 2$ model cannot be duplicated without exotic and often unrealistic assumptions on the structure of technology [see Ethier (1984)]. Nevertheless, the $\mathrm{N} \times \mathrm{N}$ model is analytically convenient, especially since in this case the effect of factor endowments on output (i.e., the Rybczynski derivatives or, equivalently, the Stolper-Samuelson effects) can be obtained by regressing output (or goods trade) on factor endowments. ${ }^{2}$

Economists have often conjectured, however, that there are more goods than factors [see, for example, Melvin (1968), Bhagwati (1972), Travis (1972), and Rader (1979)]. The reason is simple. One can easily imagine a myriad of different goods, but it is difficult to conceive of more than a handful of factors: several categories of labor, a few kinds of capital, various types of land, and several mineral and energy resources. ${ }^{3}$ Fortunately, the theoretical implications of having

\footnotetext{
${ }^{2}$ The Rybczynski derivatives are the result of first differentiating the revenue function with respect to price and second with respect to factor endowments. These derivatives relate how output moves when factor endowments change. The Stolper-Samuelson effects are simply the result of differentiating the revenue function with respect to factor endowments first and price second. These derivatives link wages and prices. Young's theorem guarantees that the two sets of derivatives are the same.

${ }^{3}$ Of course, if factors are specific to industries, then the potential number of factors increases dramatically. Some canonical trade models are predicated upon a large number of factors, such as the pure exchange model, where all factors are sector-specific, or the Ricardo-Viner model, where there is one mobile factor in addition to sector-specific factors. But these models are not the subject of much empirical work, as Leamer and Levinsohn (1995, p. 1345) remark. Also, these models are usually thought to capture short-run behavior, and not the longrun determinants of comparative advantage.
} 
more goods than factors are well-known. Ethier (1984) cites no fewer than nine works that deal with the issue, starting with Samuelson (1953).

Vanek (1968) examined extensions of the Heckscher-Ohlin model to cases in which there are more goods than factors. ${ }^{4}$ His main contribution was to demonstrate that it still was possible to obtain a version of the Heckscher-Ohlin theorem expressed in terms of trade in factor services: i.e., a country will be a net exporter of the services of factors in which it is relatively abundant. Unfortunately, in a world with more than two goods and factors, it becomes impossible to identify the factor intensity of industries and so the Rybczynski theorem and its corollary, the HeckscherOhlin theorem, can be expressed only as relationships between technology matrices, trade or output vectors, and factor endowment vectors. Still, as long as there are an equal number of goods and factors and the production techniques are common and independent, these theorems specify a unique mapping from factor endowments into output or trade.

With more goods than factors, however, most of the basic trade theorems no longer apply. The Factor Price Equalization theorem remains valid as long as endowments are not too dissimilar. Unfortunately, when there are more than two goods and factors, as Ethier (1984, p. 158) notes, "the strong Stolper-Samuleson property that commodity price changes produce unambiguous changes in all factor rewards runs into serious limitations," and only a far weaker version of the Stolper-Samuelson theorem can be maintained. Most significant for our purposes, the existence of more goods than factors renders it impossible to achieve a common one-to-one mapping of endowments into outputs. Consequently, all attempts to predict trade flows on the basis of factor endowments have relied, at least implicitly, on the "square" assumption of equal numbers of goods and factors.

It is largely because of the fact that square models generate so many powerful results that these models hold a special place in international trade theory. Although many empirical papers have focused on the Heckscher-Ohlin-Vanek (HOV) formulation of the model—which focuses on

\footnotetext{
${ }^{4}$ As Anderson (1981) points out, Travis (1964) also derived a similar result, but in the subsequent literature it has become commonly associated with Vanek's name.
} 
trade in factor services rather than commodity trade-more often researchers have sought to generate estimates of trade or production on the basis of factor endowments, relying on what we call the "factor-endowments-driven" (FED) model of production. ${ }^{5}$ Three major users of this methodology are authors seeking to test trade models [e.g., Leamer (1984), Maskus (1991), Harrigan (1995), and Davis and Weinstein (1996)]; those attempting to identify trade barriers or industrial policy interventions [e.g., Saxonhouse (1983, 1986, 1989), Leamer (1988a, b), and Noland (1993)]; and consumers of the preceding literature, who employ their estimates of trade barriers in studies of trade policy and economic growth [e.g., Edwards (1992), Levine and Renelt (1992), and Gould and Gruben (1996)].

Many of these studies have tried to predict trade flows on the basis of factor endowments. However, Harrigan (1995) was the first to realize that one can estimate Heckscher-Ohlin-type relationships by focusing on production rather than trade. ${ }^{6}$ He examined whether the production patterns of 20 OECD countries could be predicted from their factor endowments. Using 16 years of annual data, he regressed 10 manufacturing sectors on seven factors. He found that differences in factor endowments accounted for much of the variation in output; however, expressed as a percent of actual production, the average prediction error was close to 40 percent. From this evidence Harrigan concluded that the factor-abundance production model had little explanatory power.

Unfortunately, it is difficult to identify in Harrigan's work exactly why the fits were so poor. The theory is static and intended to explain cross-sectional variation, but Harrigan estimated it as a time series with country fixed effects. Consequently, his coefficient estimates are influenced by movements in technology which in general may be difficult to characterize. As Davis and Weinstein (1996) note, this makes it unclear whether the empirical failure described by

\footnotetext{
${ }^{5}$ See footnote 12 below for some examples of empirical investigations of the HOV equation.

${ }^{6}$ As Davis, Weinstein et al. (1997) have noted, the intellectual capital of the HOV theory is staked on the production side. The Factor Price Equalization, Rybczynski, and Stolper-Samuelson theorems make no use of the consumption model at all, and the Heckscher-Ohlin theorem is basically a corollary to the Rybczynski theorem with the added assumption of identical homothetic preferences.
} 
Harrigan is due to problems in the FED model of production itself or in the way in which the matrix of Rybczynski derivatives is constrained to vary across time.

The Harrigan study also raises the question of whether the FED model of production is inherently flawed because of a violation of a core assumption of the model, such as constant returns to scale or equal numbers of goods and factors, or whether there are problems in the data that prevent the model from fitting an international sample. Problems in the latter category include measurement error, missing factors, government policy, and the failure of factor price equalization in some of the countries in the sample.

The major insight in this paper is the recognition that by using Japanese prefectural data rather than cross-country data, we can substantially simplify the analysis and rule out most of the potential reasons why the FED production model might fail. ${ }^{7}$ We work with a set of regions for which there exists a technology matrix that accurately maps production into endowments. We can therefore largely rule out the possibility of failure due to scale economies, a lack of factor price equalization, measurement error, and government policy. Even in this best-case scenario, we find that the FED model of production performs miserably. This allows us to focus on two possible reasons for failure: missing factors and production indeterminacy arising from the existence of more goods than factors. Our inability to find additional factors that can help explain production patterns leads us to conclude that indeterminacy is the likely culprit.

Oddly enough, when we turn to international data which Davis, Weinstein et al. (1997) found to be poorly described by the HOV model of production, we obtain significantly better fits from regressions of output on endowments. The fact that the FED model of production describes international data better than regional data supports the notion that trade costs work to constrain the range of possible production patterns. There is an important caveat, however. The errors in cross-sectional regressions are almost twice the magnitude of those calculated by Harrigan (1995)

\footnotetext{
${ }^{7}$ Krugman (1991, p. 3) argues for this kind of approach, writing that "one of the best ways to understand how the international economy works is to start by looking at what happens inside nations. . The data will be better and pose fewer problems of compatibility, and the underlying economic forces will be less distorted by government policies."
} 
using fixed-effects estimation. We interpret these results as evidence that trade costs help resolve indeterminacy but fail to produce neat linear mappings from factor endowments into output.

\section{Dimensionality, Production, and Trade: Theory and Tests}

In this section we illustrate how production and factor endowments are linked together in models where production is determinate and where production is indeterminate. The objective is to show how theory can help us distinguish between these two possible worlds. We begin by establishing some notation. Let $\mathrm{N}$ denote the number of goods, $\mathrm{F}$ represent the number of factors, and $\mathrm{r}$ index regions (where $\mathrm{r} \in \mathrm{R}$ ). For each region $\mathrm{r}, \mathrm{X}^{\mathrm{r}}$ is the $\mathrm{N} \times 1$ vector of gross outputs, $\mathrm{V}^{\mathrm{r}}$ the $\mathrm{F} \times 1$ vector of factor endowments, and $\mathrm{B}^{\mathrm{r}}$ the $\mathrm{F} \times \mathrm{N}$ matrix of direct factor input requirements.

\section{A. Testing for Identical Production Techniques}

We now make the standard assumptions about production inherent in the HeckscherOhlin-Vanek model. First, we assume that technology is identical across regions and exhibits constant returns to scale. Furthermore, we assume that regional endowments are not too divergent so as to preclude factor price equalization (FPE), goods and factor markets are perfectly competitive, and the number of goods is at least as large as the number of factors $(\mathrm{N} \geq$ F). If these conditions are satisfied, then it can be shown that production techniques will be identical across regions, i.e. that $\mathrm{B}^{\mathrm{r}}=\mathrm{B} \forall \mathrm{r} \in \mathrm{R}$. Moreover, for each prefecture we can write: ${ }^{8}$

$$
\mathrm{BX}^{\mathrm{r}}=\mathrm{V}^{\mathrm{r}} \quad \forall \mathrm{r} \in \mathrm{R} \quad(\text { Dimension } \mathrm{F} \times 1)
$$

These R sets of equations can be expressed more compactly as

$$
\mathrm{BX}=\mathrm{V} \quad(\text { Dimension } \mathrm{F} \times \mathrm{R})
$$

where $\mathrm{B}$ is the common $\mathrm{F} \times \mathrm{N}$ technology matrix, and $\mathrm{X}$ is an $\mathrm{N} \times \mathrm{R}$ matrix whose columns consist of the output vectors for each region, and $\mathrm{V}$ is a $\mathrm{F} \times \mathrm{R}$ matrix whose columns are the

\footnotetext{
${ }^{8}$ It is important to clarify one potential source of confusion about this equation. If we let $\mathrm{J}$ denote Japan as a whole, $\mathrm{BX}^{\mathrm{J}}$ must equal $\mathrm{V}^{\mathrm{J}}$ by definition. However, as Davis, Weinstein et al. (1997) discuss in considerable detail, there is no guarantee that $\mathrm{BX}^{\mathrm{r}}$ will equal $\mathrm{V}^{\mathrm{r}}$ for each region within Japan.
} 
endowment vectors for each region. The columns of the left-hand side of equation (1) represent the measured factor content of production for each region and the columns of the right-hand side are the actual factor endowment vectors. ${ }^{9}$ Hence equation (1) tells us that the measured factor content of production should equal the actual regional endowment.

We refer to equation (1) as the Heckscher-Ohlin-Vanek (HOV) model of production. Notice that this relationship can fail because of technological differences, increasing returns, or any other reason why factor price equalization might not obtain. If we find that equation (1) does hold, however, then we can conclude that whatever violations of the HOV theorem's basic assumptions exist, they are not sufficient to undermine the theory's predictions about output.

We will take two strategies toward testing equation (1). First, following Harrigan (1995), we examine prediction errors; second, following Ethier (1984), we calculate Rybczynski "correlations." 10 To do so, we note that equality of the BX and V matrices in equation (1) implies equality for each corresponding element of the two matrices; i.e., for each factor $f$ and region $r$,

$$
\left.\left[\mathrm{B}^{\mathrm{f}} \mathrm{X}^{\mathrm{r}}\right]=\left[\mathrm{V}^{\mathrm{fr}}\right] \quad \text { (Dimension } 1 \times 1\right)
$$

where $B^{f}$ denotes the $f^{\text {th }}$ row of the technology matrix and $V^{\text {fr }}$ the $f^{\text {th }}$ element of $V^{r}$. Obviously it is too much to expect that equation (1') will hold exactly. Instead we look at the percentage deviation between the predicted factor content of production and the actual factor endowment. In practice, this involves first creating an $\mathrm{F} \times \mathrm{R}$ matrix, $\mathrm{D}$, whose elements are defined below:

$$
D^{\mathrm{fr}}=\left|\mathrm{B}^{\mathrm{f}} \mathrm{X}^{\mathrm{r}} / \mathrm{V}^{\mathrm{fr}}-1\right|
$$

If the errors are small, we conclude that the HOV model provides a reasonably accurate description of production structure. If there are substantial errors, we conclude that the model is deficient in some respect.

\footnotetext{
${ }^{9}$ Our nomenclature here follows the literature, in which the endowment estimates that are imputed from information on outputs and technology are referred to as the "measured" endowments, while the endowments taken from the data sample are termed the "actual" endowments.

${ }^{10}$ Strictly speaking, these are not true correlations but are "on average" relationships analogous to the well-known multigood comparative advantage "correlations" between exports and relative autarky prices derived by Dixit and Norman (1980) and Deardorff (1980).
} 
We could in principle examine all of the elements of D at once, but it is analytically convenient to consider two types of average prediction errors. First, looking at the column of D corresponding to a given region $\mathrm{r}$, we can compare the actual endowments and measured factor absorption for each region. Second, we can hold f fixed and consider the corresponding row of D, comparing the actual endowments and measured factor usage across all regions. In this way we distinguish how well the model fits individual regions as well as particular factors.

It is not sufficient to stop here, however. Tests of the HOV production model based on equation (1') are incomplete, since they could conceivably yield misleading conclusions in certain instances. For example, suppose that all regions had identical factor proportions but differed only in size. In this case prediction errors might be very small because larger regions just produce more of everything, but we might not have any information about whether differences in relative factor proportions are associated with outputs in the manner specified by theory. What we need is some way of addressing the question of whether differences in relative factor proportions translate into differences in observed production patterns as theory predicts.

Fortunately, this problem has already been largely worked out by Ethier (1984). With two goods and two factors, the Rybczynski theorem maintains that holding output prices constant, an increase in the endowment of some factor will generate a more-than-proportional increase in the output of the good that uses that factor intensively and a reduction in the output of the other good. In higher dimensions ( $\mathrm{N}>2$ goods, $\mathrm{F}>2$ factors), the relationship between endowments and production must be stated quite differently. ${ }^{11}$

In particular, our empirical tests impose restrictions based upon Ethier's multidimensional formulation of the Rybczynski relationship. Suppose for two regions $\mathrm{r}$ and $\mathrm{r}^{\prime} \in \mathrm{R}$ we have $\mathrm{BX}^{\mathrm{r}}=$ $\mathrm{V}^{\mathrm{r}}$ and $\mathrm{BX} \mathrm{X}^{\mathrm{r}^{\prime}}=\mathrm{V}^{\mathrm{r}^{\prime}}$. We can then subtract one equation from the other to get: $\mathrm{B}\left(\mathrm{X}^{\mathrm{r}}-\mathrm{X}^{\mathrm{r}^{\prime}}\right)=\left(\mathrm{V}^{\mathrm{r}}-\right.$ $\left.\mathrm{V}^{\mathrm{r}^{\prime}}\right)$. Premultiplying both sides by the transpose of $\left(\mathrm{V}^{\mathrm{r}}-\mathrm{V}^{\mathrm{r}^{\prime}}\right)$ yields Ethier's Rybczynski “correlation":

\footnotetext{
${ }^{11}$ Another test involves verifying that, for each industry and each factor, at least one Rybczynski derivative is negative. With the large number of sectors included in our study, this test is not particularly powerful.
} 


$$
\left(\mathrm{V}^{\mathrm{r}}-\mathrm{V}^{\mathrm{r}^{\prime}}\right)^{\mathrm{T}} \mathrm{B}\left(\mathrm{X}^{\mathrm{r}}-\mathrm{X}^{\mathrm{r}^{\prime}}\right)=\left(\mathrm{V}^{\mathrm{r}}-\mathrm{V}^{\mathrm{r}^{\prime}}\right)^{\mathrm{T}}\left(\mathrm{V}^{\mathrm{r}}-\mathrm{V}^{\mathrm{r}^{\prime}}\right)>0 \quad(\text { Dimension } 1 \times 1)
$$

For each pair of regions ( $r, r^{\prime}$ ), equation (2) says that regions with more (less) of a particular factor generally produce goods which use that factor relatively more (less) intensively. If we examine this relationship for all $r$ and $r$, we can group the left- and right-hand sides of equation (2) into two $\mathrm{R} \times \mathrm{R}$ symmetric matrices. According to theory, all the elements comprising these matrices should be non-negative, and the diagonal elements should be zeroes. For the matrix whose elements correspond to right-hand side of equation (2), it is a mathematical truism that these conditions are fulfilled. However, for the matrix comprised of the left-hand-side terms, there is no guarantee that the off-diagonal elements are non-negative.

We can improve Ethier's formulation with a slight modification. One drawback of the above approach is that it pools together information garnered from different factors. To see this, consider what theory tells us the relationship should look like for any factor f. Just as equation (1') describes the production equation of the HOV model in terms of a particular factor and region, there is an analogous expression for Ethier's multidimensional Rybczynski "correlation":

$$
\left(\mathrm{V}^{\mathrm{fr}}-\mathrm{V}^{\mathrm{fr}}\right) \mathrm{B}^{\mathrm{f}}\left(\mathrm{X}^{\mathrm{r}}-\mathrm{X}^{\mathrm{r}^{\prime}}\right)=\left(\mathrm{V}^{\mathrm{fr}}-\mathrm{V}^{\mathrm{fr}}\right)^{2}>0 \quad \forall \mathrm{f}, \mathrm{r} \text {, and } \mathrm{r}^{\prime} \quad(\text { Dimension } 1 \times 1)
$$

Equation (2') permits us to examine the data by factor and by region, whereas equation (2) pools together all of the factor evidence for any regional comparison. This is an important advantage, because if equation (2') holds for some factors but not others, then tests based on equation (2) might fail to detect failures in the theory for particular factors. This would occur if negative values on the left-hand side of equation (2') were eliminated in being summed together with one or more positive values.

How does one test a relationship like (2')? Since there are $\mathrm{FR}^{2}$ relationships, it makes sense to try to place some structure on the results to make them more interpretable. As we noted above, for each factor $\mathrm{f}$, we can arrange the results from each pairwise comparison generated by the left-hand side of equation (2') into a symmetric $\mathrm{R} \times \mathrm{R}$ matrix, $P_{V X}^{f}$. Similarly, employing this procedure for the right-hand side generates the symmetric $\mathrm{R} \times \mathrm{R}$ matrix, $A_{V V}^{f}$. We are left with $\mathrm{F}$ pairs of matrices, one pair for each factor $\mathrm{f}$, as shown below: 


$$
\left.P_{V X}^{f}=A_{V V}^{f} \quad \text { (Dimension } \mathrm{R} \times \mathrm{R}\right)
$$

As with the aggregate matrices described above, these factor-specific matrices are symmetric and have zeroes along the diagonal. Moreover, the off-diagonal elements should be non-negative.

There are two types of tests we can conduct on these pairs of matrices. First are sign tests, which entail verifying that the off-diagonal elements of $P_{v x}^{f}$ are all non-negative. (Those of $A_{V V}^{f}$ are necessarily so.) Sign tests tell us whether prefectures that are relatively more endowed with a given factor tend, on average, to produce larger quantities of commodities that use that factor intensively. Unfortunately, sign tests are problematic as a test of the relationship in equation (3) because they are insensitive to magnitudes. For example, if prefectures are very similar in their endowments but there exists some measurement error, the sign test may fail even though BX may actually be very close to $\mathrm{V}$ in most instances.

To remedy this potential drawback and to bolster our analysis, we also conduct correlation tests. For each factor $\mathrm{f}$, we can make $\mathrm{R}(\mathrm{R}-1) / 2$ pairwise comparisons between the elements comprising the symmetric matrices on the left- and right-hand sides of equation (3). The rank or raw correlation of these $R(R-1) / 2$ elements-what we call "within-factor" tests-indicate whether large differences in regional endowments of a given factor are reflected in large differences in outputs. Unfortunately, both the sign and within-factor correlation tests share the same problem inherent in tests of equation (1') outlined above: namely, success in these tests might arise simply from size variation across regions, rather than reflecting differences in factor proportions. Fortunately, we can control for the possible confounding effect of size by conducting "cross-factor" tests. For each pair of regions (r, r'), equation (2') gives us F comparisons of relative factor abundance and relative factor usage. By conducting rank and raw correlations of these $\mathrm{F} \times 1$ vectors, we can determine if differences in relative factor abundances are reflected in corresponding relative outputs.

In sum, success on this battery of tests indicates that a set of regions has identical or nearly identical production techniques, whereas failure indicates that there must be substantial regional variation in unit input requirements. These tests of the HOV production model also serve as a 
critical controlled experiment that we can draw upon in subsequent tests of the FED model. If all regions use identical production techniques, then we know that our inability to predict output on the basis of factor endowments cannot be the result of increasing returns, technological differences, fewer goods than factors, or any other reason that might cause factor-price equalization to fail. As we argue in the next section, this significantly reduces the possible causes of problems with the FED model.

\section{B. Predicting Outputs From Factor Endowments}

\section{Theory}

A major question in international trade is whether production levels and trade flows are determined by factor endowments. In this section we explore the conditions under which the Heckscher-Ohlin model guarantees such a relationship. Ultimately, we would like to write output as a linear function of factor endowments, i.e.

$$
\mathrm{X}^{\mathrm{r}}=\Omega \mathrm{V}^{\mathrm{r}} \quad(\text { Dimension } \mathrm{F} \times 1)
$$

where the $\Omega$ matrix has dimension $\mathrm{N} \times \mathrm{F}$. Equation (4) is what we call the factor-endowmentsdriven (FED) model of production. In general, output can be written as a unique function of endowments, that is independent of the endowments, only if $\mathrm{N} \leq \mathrm{F}$. Furthermore there will be a common technology matrix $\mathrm{B}$ such that $\mathrm{BX}^{\mathrm{r}}=\mathrm{V}^{\mathrm{r}} \forall \mathrm{r} \in \mathrm{R}$ only if there is factor price equalization, which in turn requires that $\mathrm{N} \geq \mathrm{F}$. Hence a necessary condition for both relations holding is that there are an equal number of goods and factors.

An alternative way about thinking about the problem is that if $\mathrm{BX}^{\mathrm{r}}=\mathrm{V}^{\mathrm{r}}$, then a unique $\Omega$ will exist only if B is invertible. Invertibility in turn requires that B is of full rank and that there are an equal number of goods and factors; and in this case, $\Omega$ equals $\mathrm{B}^{-1}$.

Notice that we have just derived a test of whether there are an equal number of goods and factors. If the HOV model of production works and B has full rank, then the FED model of production will fail if there are more goods than factors. To demonstrate this, consider what happens if $\mathrm{N}<\mathrm{F}$. If $\mathrm{N}<\mathrm{F}$, country endowments are not scalar multiples of each other, and there 
is no international factor mobility, then factor price equalization will not obtain in general, and the HOV model of production will be violated. ${ }^{12}$ In a one-good, two-factor model, for example, there is no linear relationship between endowments and output that is the same for all regions. On the other hand, if $\mathrm{N}>\mathrm{F}$ and the other conditions of the model are satisfied, the HOV model of production should apply: i.e., all regions will use identical production techniques. However, the equilibrium output vectors are no longer unique, B is not invertible, and there is no one-for-one mapping from endowments into production as postulated in (4). Thus, if there are more goods than factors we should expect equations (1') and (2') to hold but equation (4) to fail. ${ }^{13}$ This simple test based on the invertibility of B serves as our main mechanism for identifying if there are more goods than factors.

How do we assess a failure of equation (4)? Once again we are going to evaluate the success of the model by focusing on percentage prediction errors. Specifically we examine the magnitudes of $\left|\widehat{\Omega}^{n} V^{r} / X^{n r}-1\right|$, where $\widehat{\Omega}^{n}$ is our estimate of the $\mathrm{n}^{\text {th }}$ row of the $\Omega$ matrix and $\mathrm{X}^{\mathrm{nr}}$ the $n^{\text {th }}$ element of $X^{r}$. As in our tests of equation (1'), we generate average prediction errors across prefectures and across industries.

We also implement a second test, making use of the fact that somewhat more structure can be placed on the $\Omega$ matrix. Premultiplying equation (4) by $\mathrm{B}$, we obtain $\mathrm{BX}=\mathrm{B} \Omega \mathrm{V}$. Assuming that equation (1) holds, we can then substitute for BX to yield:

$$
\mathrm{V}=\mathrm{B} \Omega \mathrm{V} \quad \Rightarrow \quad \mathrm{B} \Omega=\mathrm{I} \quad(\text { Dimension } \mathrm{F} \times \mathrm{F})
$$

12 Technically, in a world with $\mathrm{N}<\mathrm{F}$ and factor mobility, factors might migrate so that FPE obtains. Then both the HOV and FED models of production would hold, and we would not be able to distinguish between a world in which there are equal numbers of goods and factors and one in which there are fewer goods than factors. However, with fewer goods than factors, we would still not expect to see equation (1) hold and equation (4) fail.

${ }^{13} \mathrm{Net}$ trade in factor services, by contrast, will remain determinate even in a world where $\mathrm{N}$ exceeds $\mathrm{M}$. In other words, the HOV trade equation remains valid. Using $r$ to denote a country, $\mathrm{W}$ to denote the world, $\mathrm{s}^{\mathrm{r}}$ to denote country r's share of world spending, and $\mathrm{T}$ to denote trade, this can be formulated mathematically as $\mathrm{BT}^{\mathrm{r}}=$ $\mathrm{V}^{\mathrm{r}}-\mathrm{s}^{\mathrm{r}} \mathrm{V}^{\mathrm{W}}$. Thus our results have no bearing on the studies which attempt to measure how well the HOV trade equation fits the empirical data.

In fact, there is a growing empirical literature on the predictive power of the HOV trade equation, and so far the reviews are mixed. Early studies, such as Maskus (1985) and Bowen, Leamer, and Sveikauskas (1987), unanimously found the model to be an empirical failure. Later studies offer a somewhat more equivocal assessment. Papers by Trefler (1993, 1995) and Davis, Weinstein et al. (1997) have shown that when modified in minor ways the HOV model has considerable explanatory power. 
where $\mathrm{I}$ is an $\mathrm{F} \times \mathrm{F}$ identity matrix. ${ }^{14}$ Similarly, it is possible to write

$$
\mathrm{X}=\Omega \mathrm{BX} \quad \Rightarrow \quad \Omega \mathrm{B}=\mathrm{I} \quad(\text { Dimension } \mathrm{N} \times \mathrm{N})
$$

Now $\mathrm{I}$ is an $\mathrm{N} \times \mathrm{N}$ identity matrix. In a world where $\mathrm{N}$ exceeds $\mathrm{F}$, equation (6) will never be satisfied because it imposes $\mathrm{N}^{2}$ linear restrictions on only NF parameters. We therefore test only equation (5) to see if the estimated parameters of the $\Omega$ matrix are weakly related to the underlying technology by imposing $\mathrm{F}^{2}$ restrictions on NF parameters.

Theory tells us that we should expect to see three possible outcomes from these experiments. If both the HOV and the FED models work, then we can conclude that endowments do determine the location of production. Similarly, if both models fail, then we can conclude that the world must violate a fundamental tenet of the HOV framework. The final possibility, that HOV works but the FED fails, indicates that the basic assumptions of the HOV model hold, but there are more goods than factors.

There are two different ways in which having more goods than factors can affect our results. First, it may be the case that there truly are fewer factors than goods. Second, it may be that we simply have omitted some important factors from our production specification. To see why this might matter, suppose that we are in a two-good, two-factor model but have data on only one factor. If one has the row of the B matrix corresponding to that factor and all the other conditions of the model are satisfied, then the HOV model would hold even with an omitted factor. On the other hand, it would not be possible to predict production structure without the missing factor. Since we do have not a complete list of potential factors, we must be open to the possibility that some factor endowments are not included in our analysis. Hence, if we find that equation (4) fails, our analysis must address the question of whether there are truly more goods than factors, or whether we have inadvertently omitted important factors. We will return to this issue in the empirical implementation.

\footnotetext{
${ }^{14}$ One could easily think of some particular vectors $\mathrm{V}$ for which the inference in equation (4) is not strictly correct, because there are matrices other than I for which the first equation holds. However, since this relationship has to hold for any $\mathrm{V}$, the only possible solution is $\mathrm{B} \Omega=\mathrm{I}$.
} 


\section{Trade Cost Tests}

Thus far, we have considered tests within the context of the success or failure of the HOV and FED models of production. A complementary approach asks what conditions will serve to eliminate production indeterminacy arising from the existence of more goods than factors.

One potential solution is to aggregate goods in such a way that $\mathrm{N}=\mathrm{F}$. It turns out, however, that aggregation solves the indeterminacy problem only in exceptional cases. ${ }^{15}$ One such stylized situation involves the existence of two factors and three goods (autos, brown shoes, and black shoes), with two goods (the shoe varieties) produced using identical techniques. In this case, it is not possible to predict how much of each type of shoe will be produced, but one could predict production of autos and total shoes by aggregating the two types of shoes. This kind of degenerate case is, of course, highly unlikely to prevail in practice. Particularly in our sample, where industries are defined at a relatively high degree of aggregation, the odds of any two industries employing exactly the same production techniques are remote, at best. ${ }^{16}$ Aside from these uninteresting and very implausible scenarios, the literature addressing the problem has typically concluded that aggregation does not offer a viable way of obtaining mappings from factor endowments into production, when $\mathrm{N}>\mathrm{F} .17$

${ }^{15}$ Of course, the B matrix provides a trivial set of weights for aggregating sectors, but weighting the outputs by their unit factor requirements reduces the FED model of production to a restatement of the HOV model.

16 Indeed, we can and did check for this possibility by verifying that no two columns in the B matrix were identical.

${ }^{17}$ Leamer (1984) attempts to use aggregation to address the indeterminacy problem, forming commodity aggregates based on how production is correlated. However, this procedure biases the results in favor of fitting the model, as it uses information on the pattern of production to predict the pattern of production.

More generally, it can be demonstrated that it is impossible to aggregate while maintaining reasonable industry definitions. Our analysis, which parallels Chang (1979) and Leamer (1994), runs as follows. Suppose that no two goods are produced with the same technology so that we are not in a degenerate case. Then arbitrarily choose a set of $\mathrm{F}$ goods, $\mathrm{X}_{1}$, and separate the technology matrix into $\mathrm{B}_{1}$, an FxF matrix corresponding to $\mathrm{X}_{1}$, and $\mathrm{B}_{2}$, a matrix of dimension $\mathrm{Mx}(\mathrm{N}-\mathrm{F})$. The $\mathrm{HOV}$ production equation is now $\mathrm{B}_{1} \mathrm{X}_{1}+\mathrm{B}_{2} \mathrm{X}_{2}=\mathrm{V}$. Since $\mathrm{B}_{1}$ is invertible, this can be written as

$$
\mathrm{X}^{*}=\mathrm{X}_{1}+\mathrm{B}_{1}^{-1} \mathrm{~B}_{2} \mathrm{X}_{2}=\mathrm{B}_{1}^{-1} \mathrm{~V}
$$

$\mathrm{X}^{*}$ is a set of $\mathrm{F}$ aggregated goods, but one cannot give this aggregate an interpretation since every element will be a linear combination (with, in general, some negative weights) of $\mathrm{N}-\mathrm{F}+1$ goods. Furthermore, even if one tried to forge ahead by regressing $\mathrm{X}_{1}$ on $\mathrm{V}$ and treating $\mathrm{B}_{1}^{-1} \mathrm{~B}_{2} \mathrm{X}_{2}$ as part of the error term, the fact that $\mathrm{X}_{2}$ is correlated with $\mathrm{V}$ means that one's estimates of $\mathrm{B}_{1}^{-1}$ will be biased and inconsistent. 
A more promising candidate for eliminating indeterminacy, suggested by Leamer (1984), is trade costs: i.e., all transactions costs, including but not limited to transportation and information costs, entailed in exchanging a commodity across geographical boundaries. ${ }^{18}$ If trade flows minimize trade costs subject to the constraint that they satisfy the HOV trade equation, there may exist a linear relationship between factor endowments and trade (and hence production) patterns. For example, one can obtain such a relation by solving the following minimization problem

$$
\begin{aligned}
& \min _{T^{r}} \sum \kappa T^{r} \\
& \text { s.t. } B T^{r}=V^{r}-s^{r} V^{W} \forall r
\end{aligned}
$$

where $\kappa$ is a vector of trade costs, $\mathrm{T}^{\mathrm{r}}$ a vector of net trade flows for country $r, \mathrm{~V}^{\mathrm{r}}$ country $\mathrm{r}^{\text {' }} \mathrm{s}$ endowment vector, $\mathrm{s}^{\mathrm{r}}$ country $\mathrm{r}^{\prime} \mathrm{s}$ share in global consumption, and $\mathrm{V}^{\mathrm{W}}$ the world endowment vector.

One problem with Leamer's approach is that it does not guarantee that the solution to the trade cost minimization problem will also cause goods markets to clear. For example, if the most capital and labor-intensive goods are traded costlessly but are only demanded in very small quantities in equilibrium, then the solution to the minimization problem will not be the solution to the general-equilibrium problem. Furthermore, as Anderson (1988) notes, Leamer's results are highly contingent on the functional form of trade costs. Leamer also implicitly assumes that international trade costs, which could drive a wedge between domestic and foreign prices, do not affect unit input requirements or consumer demands.

Although it is possible to identify theoretical problems with Leamer's approach, it is not hard to construct cases where his approach works nicely. In Figure 1 we present a model where there are two countries, three goods, and two factors ( $\mathrm{K}$ and $\mathrm{L})$. The countries' endowments are denoted by E, and their consumption points by C. If there are no trade costs, the factor-price

\footnotetext{
${ }^{18}$ Leamer actually frames the argument in terms of transportation costs, but it is more appropriate to think of these costs as international transactions costs, since distance does not enter the analysis. This framing of the issue is supported by McCallum's (1995) finding that Canadian provinces trade with each other 20 times more than they do with U.S. states located similar distances away.
} 
equalization (FPE) set is described by the hexagonal region. Trade here is indeterminate, as there are an infinite number of ways that production can be divided between the two countries. Suppose, however, that good 1 is traded at some cost. In this case the FPE set collapses as shown in Figure 2. Output of good 1 in each country (indicated by the length of the stems from the origin) is determined by the relative income levels at home and abroad. Once this is determined, the factor content of trade must be accomplished solely via the exchange of goods 2 and 3. In this manner, it is possible for trade costs to render production patterns determinate without upsetting FPE. This solution will only work in the case in which the number of goods traded at cost exactly equals $\mathrm{N}$ - F. If fewer goods are subject to trade costs, then we obtain the result portrayed in Figure 3. Here there are two factors and four goods, only one of which (good 1) cannot be traded costlessly. Each region consumes and produces good 1 in proportion to its income share, but output of the other goods is indeterminate. Hence, with many more goods than factors, identical production techniques across regions (i.e., the HOV production model works), and trade costs on certain goods, then endowments should still be able to predict the output of non-tradable goods sectors, even if the FED model fails for tradable industries.

The above framework always features some nontraded goods, when in reality most commodities are traded at some cost. Hence we should also develop the theory for cases in which trade costs are ubiquitous. While it would take us too far afield to develop the topic fully, we would at least like to provide a heuristic account, based on the analysis of Xu (1993), of how trade costs could help to eliminate the production indeterminacy. ${ }^{19}$

Consider a Heckscher-Ohlin world with two countries whose endowments are not too dissimilar, two factors (capital and labor), and a continuum of industries indexed by $\mathrm{z} \in[0,1] .{ }^{20}$ Each industry $z$ has a continuum of goods indexed by $j \in[z, 1+z]$. We assume that $j$ is a direct measure of the capital intensity of the good. We also assume that all goods have Samuelson

\footnotetext{
${ }^{19} \mathrm{Xu}$ 's model is actually more general than the one given below, as it incorporates differences in both factor abundances and technology. However, the essence of the model is captured in the version we present.

${ }^{20}$ We wish to thank Donald Davis for providing us with a clear and elegant explication of this point.
} 
iceberg trade costs, so that if $t>1$ units of a good are shipped, only 1 unit arrives. Suppose that the home country is more capital abundant than the foreign country and that initially trade costs are prohibitive. In this case the return to capital will be lower in the home country than in the foreign country. Now consider what happens if trade costs fall sufficiently to allow for trade. With lower trade costs, the home country will have a comparative advantage in the most capitalintensive goods due to the fact that capital is cheaper at home than abroad. Similarly, lower foreign wages will cause the foreign country to export the most labor-intensive goods. Goods of intermediate capital intensity will not be traded because the cost advantage in neither country will exceed the trade costs. In the limit as trade costs go to zero, FPE will obtain, and the range of non-traded goods will fall.

This structure suffices to make both production and trade determinate. There is a range of goods $\left[0, \mathrm{j}^{*}\right]$ produced in and exported from only the foreign country. Likewise, there is a range of goods [j, 2] produced in and exported from only the home country. All goods in the range [j*, j'] are not traded in equilibrium, so each country produces these goods according to its own needs. The determination of the boundaries, $\mathrm{j}^{*}$ and $\mathrm{j}$, depends inter alia on the magnitude of trade costs, the equilibrium level of demand for the various goods, and the extent of differences in the countries' endowments. Note that although there is complete specialization in all goods traded in equilibrium, this need not suggest any specialization in the industrial aggregates (hence in real-world data), since each industry incorporates goods with a range of factor intensities. Nevertheless, one can sensibly talk about the typical factor intensity of an industry, and it will generally be the case that exports are higher for more capital-intensive industries in the capitalabundant country (and vice versa for the labor-abundant country).$^{21}$

The upshot of this analysis is that trade costs may represent an important mechanism for generating production determinacy within the Heckscher-Ohlin framework. Indeed, in a world with trade costs and more goods than factors, one should expect two results. First, factor

\footnotetext{
${ }^{21}$ It is worth noting that the relationship is not necessarily linear.
} 
endowments should provide more accurate predictions of output for non-tradables than for traded goods if the latter are traded freely. Second, assuming that trade costs are more significant at the international level, but do not disturb FPE significantly, then the FED model should fit better on the international data set, ceteris paribus. ${ }^{22}$ We now turn to testing these propositions.

\section{Data Description}

This paper makes use of two data sets. The first is a slightly modified version of the data set constructed in Davis, Weinstein et al. (1997). We obtained our technology matrix, B, from that paper, but augmented the regional data so that we had information on 47 Japanese prefectures rather than ten Japanese regions. The data appendix provides details on the construction of our data set. Summary statistics are provided in Table 1. As one can see there is a large amount of regional variation in endowments due in part to the tremendous size variation of Japanese prefectures.

The second data set we use is an international data set on endowments and industry sales at the ISIC three digit level of 22 OECD countries. Details on the construction of this data set are also discussed in the data appendix. As one might expect, there is greater dispersion in output (as measured by GDP) and endowments in the international data than in the regional. However, the difference is not as large as one might suspect. Typically the coefficient of variation is only about twice as large for the international data set as for the regional data.

More interesting is the evidence on the dispersion of industries at the regional level. Tables 2 through 4 present coefficients of variation calculated in two ways. First, we hold each industry fixed and calculate a coefficient of variation using region and country based variation of given industries. This type of dispersion is quite sensitive to the size distribution of regions and countries. Not surprisingly, the data reveals that there is about twice as much dispersion in

\footnotetext{
${ }^{22}$ The qualification "ceteris paribus" is necessary because international data is likely to differ from regional data in dimensions other than trade costs. Indeed, as we discuss below, some of these differences (e.g., dissimilar production techniques across countries and larger measurement errors on international data) are likely to work in the opposite direction, impairing the performance of the FED model at the international level.
} 
international sales than in regional output. Most of this is due to two large outliers, the US and New Zealand. If we hold countries or regions fixed and examine how much variation there is across different industries, we can obtain some sense of whether industries are more specialized on regional or international data. Krugman (1991) found that there was greater regional dispersion of industries in the US than in Europe. Comparing Tables 2 and 4 we find similar evidence for Japan vis-à-vis the OECD. There is far more specialization among Japanese regions than among countries. This is what one might expect if trade costs are higher for international than for interregional trade. We now turn to investigating the implications of this hypothesis more systematically in the next section.

\section{Results}

The box below summarizes the theoretical implications of production indeterminacy. As we mentioned above, we will use both regional and international data to test the theory. The use of regional data is important because it provides us with a data set in the HOV model of production is satisfied. This enables us to establish that failures in the FED model of production are not the result of differences in production techniques. Furthermore, the regional data also allow us to examine whether the FED model performs differently for tradables, which are traded relatively freely, than for non-tradables, which are traded at substantial cost. Next we turn to international data in which trade costs are presumably more pervasive and quantitatively significant than for tradables in the regional sample. Here we examine the theoretical prediction that the FED model of production yields more accurate forecasts in the presence of trade costs. 


\section{Implications of Production Indeterminacy}

Suppose the HOV production model holds. Then $N \geq F$, leaving two possible scenarios:

If $N=F$ and $B$ has full rank, then $\Omega=B^{-1}$. Both the HOV and FED production models hold, meaning:

$$
\begin{array}{lll}
B X=V & \text { and } & X=\Omega V \\
B \Omega=I & \text { and } & \Omega B=I
\end{array}
$$

If $N>F$, then the HOV model holds but the FED model does not. This implies:

$$
\begin{array}{llll}
B X=V & \text { but } & X^{T} \neq \Omega^{\mathrm{T}} V & \text { for goods traded at no cost } * \\
& \text { and } & X^{N T}=\Omega^{\mathrm{NT}} V & \text { for non-tradables or goods subject to trade costs } \\
\Omega B \neq I & \text { and } & B \Omega \neq I &
\end{array}
$$

*assuming the number of traded goods exceeds the number of factors

\section{A. The HOV Model of Production: Tests of Equations (1') and (2') on Regional Data}

We begin our analysis by verifying that the Heckscher-Ohlin-Vanek model of production is valid for our sample of Japanese regions. In particular, we confirm that $\mathrm{BX}=\mathrm{V}$, or that each region employs the same production techniques $\left(\mathrm{B}^{\mathrm{r}}=\mathrm{B} \forall \mathrm{r} \in \mathrm{R}\right)$. As we mentioned earlier, this relationship could fail to hold as a result of increasing returns, Ricardian technical differences across regions, fewer goods than factors, or any other reason that would cause factor price equalization to fail. In this sense, our test is similar in spirit to that used by Davis, Weinstein et al. (1997), with one difference. In that paper, it was crucial that households consumed in the same regions in which they produced, so regional trade vectors could be constructed. Since the consumption theory is irrelevant for our tests of the Rybczynski theorem, however, it is not essential that all workers in each prefecture conduct their consumption in that location. We need simply to have accurate production and factor endowment data for each prefecture. This enables us to use data from all 47 Japanese prefectures as opposed to the 10 aggregated regions used by Davis, Weinstein et al. Our X vector contained data on gross output for 29 sectors for each 
prefecture, and our V vector included three factors: workers with less than a college education, college-educated workers, and capital. ${ }^{23}$

Table 5 presents the average prediction errors of the HOV model of production. The prediction errors are generally quite small, averaging $13 \%$ across all observations (where each observation is prefecture-factor specific). As explained earlier, we also calculate average errors over each prefecture and over each factor. There are few outliers among the prefectures; only three have average errors in excess of $25 \%$, and none has an average error greater than $33 \%$. Among the factors, the model works best for capital and worst for non-college-educated labor.

Figures 4 and 5 present plots of the predicted and actual factor endowments for each prefecture. Since we do not want differences in prefectural size to affect our results, each observation is deflated by the total amount of the corresponding factor for Japan and also in Figure 5 by the square root of the region's GDP. The graphical evidence confirms our basic intuition from Table 1. To the extent that economies of scale or technological differences exist, they are not significant enough to invalidate the HOV production predictions. This evidence corroborates the findings of Davis, Weinstein et al. (1997) for more aggregated regions in Japan: production techniques are (approximately) identical across Japanese prefectures, and the HOV model of production performs very well in areas where it is reasonable to assume factor price equalization.

We also conduct the sign and correlation tests suggested by Ethier. Recall that the sign test entails an examination of the off-diagonal elements of the three matrices (one for each factor) corresponding to the left-hand side of equation (3). According to theory, the R(R-1)/2 offdiagonal elements, which for our sample involves 1,081 possible pairwise comparisons of different prefectures for each factor, should all be non-negative. Once again, this is a test of whether prefectures that are relatively more endowed with a given factor tend to produce larger quantities of products that use that factor intensively.

\footnotetext{
${ }^{23}$ See the Data Appendix for information on how the sample was constructed.
} 
The results from these sign tests are presented in Table 6. Of the 3,243 possible sign checks, only 5.2\% (168) were negative. Without a well-specified null, it is difficult to say whether predicting $95 \%$ of the signs correctly is good or bad. In order to get a sense of how a random mix of output and endowment vectors would perform, we randomly assigned actual endowment vectors to actual output vectors and reran the tests. These simulated results revealed that if outputs and endowments were independently distributed, slightly more than $50 \%$ of the signs were negative. While this experiment enables us to reject the hypothesis that the real data were generated by a coin flip, it is unfortunately not a very meaningful test, since no one believes that output and endowments are completely uncorrelated. However, based on the sign test, it seems reasonable to conclude that regions more endowed with a particular factor generally produce more outputs intensive in that factor. In this sense, the data corroborate Ethier's Rybczynski "correlation."

Our second test of Ethier's multidimensional Rybczynski formulation uses the correlations between the elements comprising the matrices on the left- and right-hand sides of equation (3). First, we conduct "within-factor" tests, holding f constant and examining the variation across prefectures in the endowment and utilization of a given factor. The results of this experiment are reported in the second panel of Table 6. The rank and raw correlations exceed 0.95, indicating that differences in production structures across prefectures are very tightly linked with differences in factor endowments, in a manner consistent with theory. Of course, it is possible that this result is being driven by size differences rather than differences in relative factor endowments.

To eliminate the possibly confounding influence of size-based variation, we also conduct "cross-factor" tests. Here we hold constant the prefecture pair and examine correlations between the measured and actual absorption of factors. In effect, this test tells us whether relative factor abundances translate into relative differences in production structure, in accordance with the HOV production model. The bottom panel of Table 2 reports the cross-factor correlations. The average raw correlation (averaged across all 1,081 prefecture pairs) was 0.84 , and the average rank correlation was 0.78 . Though somewhat lower than the within-factor correlations, these 
results still manifest a close connection between outputs and factor endowments as posited by the HOV production model. We believe that this is the first empirical verification of the Ethier's multidimensional Rybczynski “correlation.”

\section{B. Assuming the Even Case: Tests of Equations (4) and (5) for Regional Data}

Thus far we have established that the Heckscher-Ohlin-Vanek production model describes the regional data quite well. However, the links between endowments and production that we have explored so far have been "correlations" that one can derive from the assumptions of the HOV model. The question examined in this section is whether the data support a stronger relationship between factor endowments and production. In particular, is there a linear, one-toone functional relationship between factor endowments and outputs, or are "correlations" between these two variables the most that we can expect to obtain? As noted earlier, this amounts to asking whether there are an equal number of goods and factors.

To examine this question, we regressed output on factor endowments. Before discussing the results, we need to address three minor econometric issues. First, our dependent variable is truncated at zero, and even though only nine observations were zeros, we decided to use a Tobit procedure to correct for a bias in these industries. ${ }^{24}$ Second, larger regions are likely to have larger errors, so it is important to correct for heteroskedasticity. Following much of the literature, we deflated all observations by the square root of prefectural GDP. ${ }^{25}$ Third is the issue of whether to include a constant term. In a model with equal numbers of goods and factors, a constant would not be necessary unless the error did not have a mean of zero. If we assume that the error incorporates omitted factors, then there is good reason for not forcing the error term to have a mean of zero. In a world with more goods than factors, the equation is misspecified with or without the constant. Since there seemed to be good arguments both for including and

\footnotetext{
${ }^{24}$ The industries with zeros in them were rubber, leather, and non-ferrous metals.

${ }^{25}$ In an alternative specification we adjusted for heteroskedasticity using endogenous weights, where the weights were chosen by assuming that the variance of the error term is proportional to GDP raised to some power. The results were qualitatively similar to those obtained using the square root of GDP as the weight.
} 
excluding the constant, we ran the model both ways. We report only the results from the regressions with a constant, because the results without the constant were similar although the fits were somewhat worse.

The results of regressing $\mathrm{X}$ on $\mathrm{V}$ are presented in Table 7 . We report standard errors to indicate the precision of the point estimates. It is often the case that one or more of the coefficients is statistically significant and in almost all specifications we can reject the hypothesis of zero slopes. It is important to recognize, however, that without an alternative hypothesis we cannot provide an interpretation of a coefficient that is statistically different from zero. As long as $\mathrm{BX}=\mathrm{V}$, output and factor endowments will be correlated, as Ethier has demonstrated theoretically and we have verified empirically. However, this does not imply that $\mathrm{X}$ is a wellbehaved function of $\mathrm{V}$.

In Table 8, prediction errors are expressed as percentages of the actual values. ${ }^{26}$ We have calculated average deviations for each prefecture (across all industries) and for each industry (across all prefectures). Strikingly, the average error is more than an order of magnitude larger than that obtained when we compared BX and V. The typical error exceeds $300 \%$-almost 25 times larger than the $13 \%$ average prediction error for factor endowments shown in Table 1. What makes this enormous discrepancy even more astonishing is the fact that our B matrix is given as data, while our $\Omega$ matrix was estimated in a way designed to minimize the residuals. ${ }^{27}$

Figure 6 plots predicted and actual output levels. Output in every sector has been divided by the total Japanese amount in that sector, so all points are distributed between zero and one. The plots reveal several interesting features of the data that are harder to see in Tables 7 and 8 .

\footnotetext{
${ }^{26} \mathrm{We}$ dropped the nine observations with zero reported output, for which this measure is undefined. We also acknowledge a potential problem with this measure: it may generate exceptionally large errors for observations in which actual production is close to zero and predicted production is negative. Although this possibility exists, it does not explain why we obtain such large average errors. Relatively few points (nineteen in Figure 5, three in Figure 6) fall into this category, and the average error for these observations is $348 \%$, which is not much larger than the average error for the entire sample.

${ }^{27} \mathrm{We}$ also tried regressing $\mathrm{V}$ on $\mathrm{X}$. In general, this produced tighter fits than those obtained from using the Japanese technology matrix and almost all coefficients could not be statistically distinguished from the values of the B matrix. Unfortunately with 30 parameters to estimate (29 coefficients plus a constant) and only 47 data points, the standard errors were quite large. Since our tests had very little power, we decided not report the results.
} 
First, there is a lot more variance in the distribution of normalized output than in the distribution of normalized factor endowments. Indeed, the median variance of normalized output is 17 times larger than the median variance of normalized endowments. Second, there are many more extreme outliers in the production data than in the factor endowment data. The average maximum value in the production data was eleven times larger than the median value, while the maximum/median ratio for the endowment data was only about two. One possible reason for this difference in variances is the existence of Jones magnification effects. Alternatively, far greater variation in production patterns than in factor endowments is also consistent with production indeterminacy. Whatever the reason for these extreme outliers in virtually every industry, their existence means that the $\mathrm{R}^{2}$ 's tend to overstate the ability of regressions to fit the typical point. ${ }^{28}$

We care not only about the accuracy of the model, but also about the interpretation of the coefficients. We argued previously that if $\mathrm{BX}=\mathrm{V}$ (as in our data set) and if $\mathrm{X}=\Omega \mathrm{V}$, then it must be the case that $\mathrm{B} \Omega=\mathrm{I}$. In other words, if there is a one-to-one relationship between factor endowments and outputs, then there should be a relationship between input requirements (the elements of B) and the coefficients obtained by regressing output on factor endowments. In order to test whether our coefficients are capturing the underlying technology, we regressed output on factor endowments and imposed the nine linear constraints implied by the relationship $\mathrm{B} \Omega=\mathrm{I}$. The appropriate test uses the Wald criterion, which has a $\chi^{2}$ distribution with nine degrees of freedom. We used two estimating methods, iterative and non-iterative seemingly-unrelated regression. The critical value (1\% level) of the Wald statistic was 22, but we obtained 1403 and 1053, for the iterative and non-iterative tests, respectively. The data clearly reject the hypothesis that our estimated coefficients are actually Rybczynski derivatives, since they are not related to technology in the manner required by theory.

Thus, our results using regional data demonstrate that the FED model fails to hold. Why is this so? Since previous studies have used international data, they have been unable to

\footnotetext{
${ }^{28}$ One approach to dealing with these outliers is to use an estimator obtained by minimizing absolute deviations. We reran our tests using a minimum absolute deviations estimator, but the results remained qualitatively similar.
} 
distinguish among the many potential reasons that the FED model of production might fail. However, $\mathrm{BX}=\mathrm{V}$ in our regional data, so we can eliminate virtually all of the problems that made Harrigan's (1995) results difficult to interpret. Technological differences (e.g., increasing returns), lumpy regions, regional industrial policy, or any other reason that might cause factor price equalization to fail within Japan would cause both $\mathrm{BX}=\mathrm{V}$ and $\mathrm{X}=\Omega \mathrm{V}$ to fail. ${ }^{29}$ Similarly, if there were fewer goods than factors, we would either have found both relationships failing or, with factor mobility, both working. Since the first relationship holds and the second does not, either the B matrix is not invertible due to the existence of more goods than factors, or our analysis has omitted some important factors.

\section{Missing Factors}

Since it is impossible to be certain that all relevant factors have been included, there is no way to prove that the structure of production is indeterminate. ${ }^{30}$ For example, college graduates who studied engineering may represent a different type of labor than those who majored in English. Indeed, every individual may constitute a different factor. However, there is a danger in using factors that are excessively disaggregated, since they may generate tautologically true relations between, say, agricultural workers and agricultural output. Moreover, if our tests fail because of the unavailability of data on finely specified factors, then the theory itself is ultimately not very useful, since researchers do not have access to this type of information in practice. We therefore focus on the set of factors that can be found in national or international data sets to see if these additional variables can improve the fit of the FED model. ${ }^{31}$

\footnotetext{
${ }^{29}$ See Courant and Deardorff (1992) for a discussion of problems arising from lumpiness.

${ }^{30}$ This is related to the more general problem of determining what are economically meaningful factors and goods. As Melvin (1968, p. 1265) and Leamer and Levinsohn (1995, p. 1363) acknowledge, we have not made much progress toward answering this fundamental question.

${ }^{31}$ One possible approach to searching for omitted factors is to test if the residuals have a factor analytic structure. The idea being that if there were omitted factors, they might turn up in the residuals. At the suggestion of a referee we conducted principal components analysis of the residuals. This did uncover a variety of correlations between residuals across sectors. Unfortunately, it is difficult to interpret these results. The problem with this approach can be seen by contemplating a three-good, two-factor model. While this is a classic case of indeterminacy the aggregate resource constraint will impose a clear structure on the residuals. If one region has low output in sectors one and three then output in sector two must be high and vice versa. Hence correlations
} 
Previous studies using international data suggest that additional factors (for which we can obtain measures) are unlikely to provide great improvements of the fits of cross-sectional regressions of trade on factor endowments. For example, when Leamer (1988b) looked at the question of how many factors should be included in a model predicting international trade flows on the basis of factor endowments, he found that he could reject models using more than nine (out of eleven potential) factors. Many of the factors that Leamer considered potentially relevant for international trade, such as illiterate workers, tropical land, desert land, coal production, oil and gas production, and mineral production are either non-existent in Japan or exist only in extremely small amounts. Consequently, it is doubtful that these factors significantly affect Japanese production. ${ }^{32}$ Even before we begin the search for missing factors, then, there is reason to be skeptical that adding more factors will greatly improve the fits.

The most obvious missing factor is land. In principle, we could have used eight different land factors, but since many of the land categories just represent different types of fields or construction, we decided to use two aggregated land variables. The first category was usable urban and farm land, and the second consisted of undeveloped mountain and forest land. To consider the effects of using finer measures of human capital, we also decomposed our two measures of labor endowments into four educational classes: 4-year college and above, 2-year college, high school, and less than high school.

We considered three specifications: (1) the basic three-factor model, with unskilled labor, skilled labor, and capital; (2) a five-factor model, with the original three factors plus two types of land; and (3) a seven-factor model, with four categories of labor, two land variables, and capital.

Prediction errors and $\mathrm{R}^{2}$ 's for the last two specifications are presented in Tables 9a and 9b. (Complete regression results are reported in Table A1 and A2 of the Results Appendix.) Overall, there is some improvement in the adjusted $\mathrm{R}^{2}$ 's of the regressions, especially in land-

among residuals will quite naturally occur even in the absence of omitted factors. Thus, while factor analysis shows finds some correlation our residuals, we are hesitant to interpret this as evidence in favor of omitted factors.

${ }^{32}$ Japan has no deserts or tropical land. Leamer (1984) reports that less than $1 \%$ of the labor force is illiterate in Japan. Furthermore, only $0.1 \%$ of the labor force is employed in mining. 
intensive sectors like agriculture. However, the average prediction errors do not improve. Even after incorporating additional factors, the FED production model yields prediction errors that are around 25 times larger than those obtained from the HOV model of production. Thus, additional factors do not contribute to the predictive power of the FED production model.

Through statistical tests, we can determine more formally the optimal number of factors. In particular, we followed Bowen et al. (1987), Leamer (1988b), and Trefler (1995) in applying the Schwartz criterion:

$$
\log \left(\mathrm{L}_{\mathrm{i}}\right)-\mathrm{p} / 2 * \log (\mathrm{n})
$$

where $L_{i}$ is the maximized likelihood under hypothesis $i, p$ is the number of parameters and $n$ is the number of observations. The preferred specification is the one with the largest Schwartz criterion. The Schwartz criterion has a number of inherent advantages: it is derivable from Bayesian principles, it performs well in Monte Carlo studies, and it asymptotically identifies the correct model with probability one. ${ }^{33}$

Table 6 shows that the basic three-factor model is the preferred specification, as evaluated by the Schwartz criterion. Combined with the fact that equation-by-equation estimation using more factors did not produce better estimates of production, this evidence suggests that missing factors (at least those for which we can obtain data) cannot explain the poor fit of the FED production model. We conclude that production indeterminacy is a major problem for this data sample.

\footnotetext{
${ }^{33}$ One referee made the useful suggestion that we employ the likelihood ratio test. By this standard, the seven-factor model performs best, with a test statistic of $\chi_{[116]}^{2}=270$ (p-value $\left.=0.000\right)$ relative to the three-factor model, and $\chi_{[58]}^{2}=126(\mathrm{p}$-value $=0.000)$ relative to the five-factor model. This divergence between the results obtrained from the likelihood ratio test and those from the Schwartz criterion is not unusual. Indeed, the authors of Bowen et al. (1987), Leamer (1988b), and Trefler (1995) would have all chosen more highly parameterized specifications had they used the likelihood ratio test rather than the Schwartz criterion. These discrepancies arise from the fact that the two procedures answer different questions. The likelihood ratio test gives the probability of finding points where our data are, assuming that the null hypothesis is true. By contrast, the Schwartz criterion takes the data distribution as given and asks which model specification best describes the data. Our analysis is more concerned with the latter question.
} 


\section{Trade Costs and Indeterminacy}

We argued earlier that trade costs may help resolve production indeterminacy arising from the existence of more goods than factors. This provides us with two additional ways to analyze the data. First, we examine whether there are any differences between the performance of the FED model across tradable and non-tradable sectors in the regional data. Then we employ the same battery of tests used earlier on an international data set, where trade costs are likely to be ubiquitous, and compare the results with those obtained previously on regional data.

\section{Trade Costs and Regional Data}

Figure 3 demonstrates that in a data set where the number of traded goods exceeds the number of factors and in which certain sectors are traded at cost while other sectors are freely traded, the FED model should work for non-traded goods but not for tradables. This is precisely what we see in the regional data. The average prediction error for non-tradable sectors is only $20 \%$, which is quite close in magnitude to the $13 \%$ average error obtained from tests of the HOV model of production. By contrast, the average prediction error for manufactures exceeds $400 \%$, or 20 times that for non-tradables. This huge divergence is consistent with a world in which trade costs partially alleviate the production indeterminacy arising from the existence of more goods than factors.

\section{Testing the HOV Model on International Data}

We now examine how our results change when we apply the same tests used on Japanese prefectural data to cross-country data. There are two principal differences between the two types of data. First, technology differences, measurement errors, and other problems are likely to plague the HOV framework when applying it to international as opposed to regional data. Most of these problems are likely to generate worse fits for both the HOV and the FED models of production. The second important difference, higher trade costs at the international level, has differential effects on the two models. To the extent that trade costs mitigate indeterminacy, the 
FED model may perform better on international than on regional data, even if the HOV model fails at the international level. Whether this is actually the case is an empirical question to which we now turn.

We begin by first examining how well the HOV model of production describes the international data. In Table 11, we calculate the average percentage deviations between BX and $\mathrm{V}$ for international data, just as we did for the regional sample in Table $5 .{ }^{34}$ The fit of the HOV model is far worse at the international level. The average prediction error $(|\mathrm{BX}-\mathrm{V}| / \mathrm{V})$ is $81 \%$ for international data, or about six times larger than the $13 \%$ obtained using regional data. ${ }^{35}$ Notice that even the smallest error for the cross-country sample (22\% for Finland) exceeds the average error for the regional data.

Reinforcing this point are the results obtained from running the Rybczynski "correlation" tests on the international data. Of course, given that $\mathrm{BX} \neq \mathrm{V}$, there is no sound theoretical foundation for performing these tests at the international level. However, when juxtaposed with the regional results, the international results provide a useful indication of the tests' explanatory power. Table 12 shows that the multidimensional Rybczynski "correlation" performs relatively poorly at the international level. Of the 570 possible sign checks, 154 elements (27\%) have the wrong sign, compared to only $5 \%$ in the tests using prefectural data. In general, the within-factor correlations are far lower than the extremely high values obtained for Japanese regions. More significantly, when we eliminate the influence of size by conducting cross-factor correlations, we obtain values approximating 0.35 rather than the 0.81 obtained using regional data. At the international level, there is not the tight link between technology, factor endowments, and outputs predicted by the HOV model and prevailing at the regional level. This tends to support the growing literature that suggests that there exist important differences in international production techniques.

\footnotetext{
${ }^{34} \mathrm{We}$ could not include Japan in our sample since it would fit by construction.

35 In an earlier draft, we reported a higher number for a sample that included the Netherlands. This was due to an incompatibility of the Netherlands data with the rest of the sample. We therefore have deleted the Netherlands from the sample.
} 


\section{Testing the FED Model on International Data}

We next examine the FED model using a cross-section of countries. Having established that our sample of countries does not use identical production techniques and given that data problems such as measurement error are likely to be more severe for countries than for regions, we might reasonably expect the fits of the FED model to be worse on the international data. However, it is possible that higher trade costs at the international level could work in the opposite direction, leading to better fits of the FED model.

We address this empirical question by regressing output on factor endowments for the OECD, using the same set of manufacturing industries employed in the analysis of prefectures. ${ }^{36}$ In our international regressions, we include the three factors used in our basic specification, as well as arable land and mineral endowments. We add the latter two factors because they have been used in previous studies, and because they are likely to be more relevant for international comparisons.

One striking feature of the results is that the explanatory power of these regressions, as measured by the adjusted $\mathrm{R}^{2}$, is much higher than those obtained for the regional sample (cf. Tables 9a and 9b). As Table 13 indicates, the regressions of output on factor endowments using international data have an average $\mathrm{R}^{2}$ of 0.86 and an average adjusted $\mathrm{R}^{2}$ of 0.84 -almost double those of our five-factor runs on prefectures. ${ }^{37}$ The high adjusted $\mathrm{R}^{2}$ 's obtained from the international regressions are of the same magnitude as those obtained in other studies of this type,

\footnotetext{
${ }^{36}$ Note that the sample used in testing the FED model of production is different from that used to test the HOV model of production. The reason for the difference in sample coverage is as follows. To compare $\mathrm{BX}=\mathrm{V}$, we needed production data on all 29 sectors. Thus, we had to omit some OECD countries for which we did not have the necessary data (e.g., Great Britain), and we included a number of non-OECD countries for which we did have this data (e.g., Argentina). We could have included more nations in the regressions of X on V, but we elected to use only the OECD countries to facilitate comparisons with previous studies by Harrigan (1995) and Davis and Weinstein (1996).

${ }^{37} \mathrm{We}$ were also concerned that the higher $\mathrm{R}^{2} \mathrm{~s}$ might be the result of using only 22 observations and 6 regressors, so we also reran our prefectural results with only 22 prefectures but obtained $R^{2}$ 's and adjusted $R^{2}$ 's similar to those obtained from runs with 47 prefectures.
} 
such as Harrigan (1995) and Davis and Weinstein (1996), and provide a preliminary indication that the FED model performs better at the international level than at the regional level. ${ }^{38}$

Turning to the prediction errors, which we consider to be a more telling measure of the model's accuracy, we find that the factor-endowment-driven production model fares worse than it did in previous studies of international data. The average prediction error is $67 \%$, or more than 1.5 times the value reported by Harrigan in a time-series analysis of the same data. ${ }^{39}$ The crosssectional variation in OECD output appears even harder to explain than the time-series variation. Nonetheless, like the $\mathrm{R}^{2}$ 's, the prediction errors exhibit better performance for the international sample than for the regional sample. The $67 \%$ average prediction error is only one-sixth as large as that obtained for the same tradable industries using regional data. These results cast further doubt on the conjecture that missing factors may be explaining our regional results. If missing factors are important in explaining the poor fits of the regional runs, then these missing factors must be relatively unimportant in explaining international specialization. Since most missing factors that one might think of would matter more for international rather than intranational specialization, the possibility that missing factors are driving our results seems even more remote.

Trade costs, however, do offer a potential explanation for the superior international fits. ${ }^{40}$ It is reasonable to conjecture that trade costs are larger and more pervasive at the international level, and thus eliminate more of the overall indeterminacy. If so, the high $\mathrm{R}^{2}$ 's obtained from international data may tell us less about the performance of the factor-endowments-driven production model per se than about the interaction between the production model, the consumption model, and trade costs.

\footnotetext{
${ }^{38}$ Leamer (1984) obtained $\mathrm{R}^{2}$ 's of around 0.6 , but his data sample included a much larger and more diverse set of countries than our study and the other two papers mentioned in the text.

${ }^{39}$ Aside from the fact that we use cross-sectional data and Harrigan used time-series, the main reason for the difference in the fits is that we include two countries that are large outliers in productivity and endowments that were dropped from Harrigan's analysis: Turkey and Yugoslavia. If we had dropped these countries our fits would have improved, but since our point was to show that the international fits are significantly better than the regional ones, we were hesitant to trim the sample in our favor.

${ }^{40}$ Another possibility is that the higher variance in the international data makes it easier to obtain higher $\mathrm{R}^{2}$. To correct for this possible bias, we deleted the largest and smallest countries in the sample (the US and New Zealand). As one can see in Table 3, this reduces the variation in the international sample to a level similar to that in the regional. Using this smaller variance sample had no impact or actually improved the international fits.
} 
In summary, the production estimates derived from regressions of outputs on factor endowments are far from perfect at the international level, with an average prediction error of 67\%. As at the regional level, there appears to be a significant amount of production indeterminacy, consistent with the existence of more goods than factors. However, the output estimates for the OECD sample are substantially more accurate than those obtained for the regional one. At first glance, this finding seems odd, since identical production techniques prevail across Japanese prefectures but not across countries. We can explain this discrepancy, along with the dramatically better fits of the FED model for non-tradables than for tradables within the regional sample, by invoking trade costs. In theory, trade costs can impose some structure on production patterns when there are more goods than factors; in practice, we find that production indeterminacy is lowest in contexts where we would expect trade costs to be highest.

Notice that this result is precisely the opposite of what is commonly assumed in empirical analysis. Several investigators [e.g., Saxonhouse (1983, 1986, 1989), Leamer (1988a, 1988b), and Noland (1993)] have regressed trade on factor endowments and then interpreted large residuals as an indication of trade barriers. Our results suggest that the residuals will be larger in the absence of trade barriers and other trade costs. Using these residuals to estimate trade barriers is therefore likely to produce a backward result. Indeed, our analysis provides an explanation for the puzzle identified by Pritchett (1996), namely the negative correlations between Leamer's (1988b) measures of openness and observed measures of tariffs, non-tariff barriers, and price distortions.

\section{Conclusion}

Trade economists have long known that, if there were more goods than factors, it would be impossible to predict outputs solely on the basis of factor endowments. However, for the most part the implications of this theoretical conclusion have been disregarded. In empirical work, it is often assumed that the world behaves "as if" production were determinate. Theorists, too, have sometimes dismissed the possibility of production indeterminacy, as exemplified by Xu's (1993) 
contention that "the problem of indeterminate trade pattern should be regarded as an intellectual curiosity, rather than a real world phenomenon."

However, in this paper we demonstrate that production indeterminacy is substantial in the type of real-world data sets typically used by empirical trade economists. Moreover, we discover that the degree of indeterminacy is greatest when trade barriers and trade costs are relatively low, e.g., for regional data and for manufactured goods.

We arrived at these conclusions by utilizing both regional and international data. Using regional data, we verified the HOV model of production and the multidimensional Rybczynski relationship derived by Ethier. In doing so, we established that the regional data sample was not subject to many of the possible reasons that the HOV model might fail-e.g., scale economies, heterogeneous technologies, regional industrial policy, lumpy regions, and measurement error. Given this, our finding that the FED model of production performs terribly at the regional level suggests either that the world is best described as having more goods than factors, or that there are missing factors. Unable to identify additional factors that improved our predictions of production patterns, we therefore concluded that the "square" assumption of equal numbers of goods and factors does not provide a good approximation of reality.

For international data, by contrast, the HOV model of production is an empirical failure. Countries do not appear to use identical techniques of production. Nonetheless, when we used international data on factor endowments to predict outputs, the regression fits (as measured by $\mathrm{R}^{2}$ ) were substantially better and the prediction errors much smaller than they were for the regional data set. We surmised that the improved ability to predict production patterns at the international level is the result of trade barriers and other international trade costs putting some structure on national production patterns. Much the same phenomenon was observed in the regional data, where prediction errors were 20 times lower for non-tradables than for tradables. These results thus support Leamer's (1984) and Xu's (1993) contention that trade costs act to reduce production indeterminacy. They do not completely eliminate the indeterminacy, however. 
A practical implication of our results is that one should exercise great caution in interpreting regressions of production (or commodity trade) on factor endowments. These regressions typically generate high $\mathrm{R}^{2}$ 's on international data, but this result is merely reflective of the correlation between trade and factor endowments and of the interaction of these two elements with trade costs. The estimated coefficients do not correspond to Rybczynski derivatives in the theoretically specified manner.

A primary application of such regressions has been the estimation of trade barriers. Some previous researchers [e.g., Saxonhouse (1983, 1986, 1989) and Leamer (1988a, 1988b)] have regressed trade on factor endowments and then interpreted the residuals as an indication of trade barriers. Ironically, we find that the residuals are likely to be much larger in the absence of trade barriers and other trade costs. Our results therefore explain the disconcerting finding of Pritchett (1996): the observed negative correlation between Leamer's (1988b) measures of openness and conventional measures of tariffs, non-tariff barriers, and price distortions.

One important finding of ours is that, within sets of regions that are not separated by trade barriers or segmented by high trade costs, the strongest relationship between outputs and factor endowments that can be maintained is the HOV model of production. However, trade costs do render a certain degree of determinacy at the international level. This two-tiered structure of production suggests that theorists and empirical economists should try to build trade costs explicitly into their trade models.

In order to make progress in understanding the location of production (and hence patterns of commodity trade), it is necessary to acknowledge that the world is not square. Instead of treating production indeterminacy as a nuisance to be eliminated by assumption, we must confront this phenomenon directly. 


\section{REFERENCES}

Anderson, James E. 1981. "Cross-Section Tests of the Heckscher-Ohlin Theorem: Comment," American Economic Review, 71 (December), pp. 1037-1039.

Anderson, James E. 1988. "Comment on 'Cross-Section Estimation'," in Robert C. Feenstra, ed., Empirical Methods for International Trade (Cambridge: MIT Press), pp. 83-87.

Antweiler, Werner and Daniel Trefler. 1996. "Increasing Returns and All That: A View from Trade," mimeo, April 22.

Bhagwati, Jagdish (1972) "The Heckscher-Ohlin Theorem in the Multi-Commodity Case," Journal of Political Economy, 80 (5), pp. 1052-1055.

Bowen, Harry P., Edward E. Leamer, and Leo Sveikauskas. 1987. "Multifactor, Multicountry Tests of the Factor Abundance Theory," American Economic Review, 77 (December), pp. 791-809.

Chang, Whinston 1979. "Some Theorems of Trade and General Equilibrium with Many Goods and Factors," Econometrica, 47 (May), pp. 709-726.

Courant, Paul N. and Deardorff, Alan V. 1992. "International Trade with Lumpy Countries," Journal of Political Economy, 100 (February), 198-210.

Davis, Donald R. 1995. "Intra-Industry Trade: A Heckscher-Ohlin-Ricardo Approach,” Journal of International Economics, 39 (November), pp. 201-226.

Davis, Donald R. 1997. "Critical Evidence on Comparative Advantage? North-North Trade in a Multilateral World," Journal of Political Economy, October.

Davis, Donald R., David E. Weinstein, Scott C. Bradford, and Kazushige Shimpo. 1997. "Using International and Japanese Regional Data to Determine when the Factor Abundance Theory of Trade Works," American Economic Review, June.

Davis, Donald R. and David E. Weinstein. 1996. "Does Economic Geography Matter for International Specialization?", NBER Working Paper \#5706, August.

Dixit, Avinash K. and Victor D. Norman. 1980. Theory of International Trade. Cambridge: Cambridge University Press.

Deardorff, Alan V. 1980. "The General Validity of the Law of Comparative Advantage," Journal of Political Economy, 88, pp. 941-957.

Deardorff, Alan V. 1984. "Testing Trade Theories and Predicting Trade Flows," in Ronald W. Jones and Peter B. Kenen, eds., Handbook of International Economics, vol. I (Amsterdam: Elsevier Science), pp. 467-517. 
Edwards, Sebastian. 1992. "Trade Orientation, Distortions, and Growth in Developing Countries," Journal of Development Economics, 39, pp. 31-57.

Ethier, Wilfred J. 1984. "Higher Dimensional Issues in Trade Theory," in Ronald W. Jones and Peter B. Kenen, eds., Handbook of International Economics, vol. I (Amsterdam: Elsevier Science), pp. 131-184.

Feenstra, Robert C., Robert E. Lipsey, Harry P. Bowen "World Trade Flows, 1970-1992, with Production and Tariff Data," NBER Working paper \#5910.

Gould, David M. and William C. Gruben. 1996. "The Role of Intellectual Property Rights in Economic Growth,” Journal of Development Economics, 48, pp. 323-350.

Harkness, Jon. 1978. "Factor Abundance and Comparative Advantage," American Economic Review, 68 (December), pp. 784-800.

Harrigan, James. 1995. "Factor Endowments and the International Location of Production: Econometric Evidence for the OECD, 1970-1985," Journal of International Economics, 39 (August), pp. 123-141.

Harrigan, James. 1996. "Technology, Factor Supplies and International Specialization: Testing the Neoclassical Model," University of Pittsburgh, mimeo.

Helpman, Elhanan and Paul R. Krugman. 1985. Market Structure and Foreign Trade: Increasing Returns, Imperfect Competition and the International Economy. Cambridge: The MIT Press.

Jones, Ronald 1957. "Factor Proportions and the Heckscher-Ohlin Model," Review of Economic Studies, 24, pp. 1-10.

Krugman, Paul. 1991. Geography and Trade. Cambridge: MIT Press.

Leamer, Edward E. 1984. Sources of International Comparative Advantage: Theory and Evidence. Cambridge: MIT Press.

Leamer, Edward E. 1988a. "Cross-Section Estimation of the Effects of Trade Barriers," in Robert C. Feenstra, ed., Empirical Methods for International Trade (Cambridge: MIT Press), pp. 51-82.

Leamer, Edward E. 1988b. "Measures of Openness," in Robert E. Baldwin, ed., Trade Policy Issues and Empirical Analysis (Chicago: University of Chicago Press), pp. 147-200.

Leamer, Edward E. 1994. "Trade, Wages and Revolving Door Ideas," NBER Working Paper \#4716.

Leamer, Edward E. and Harry P. Bowen. 1981. "Cross-Section Tests of the Heckscher-Ohlin Theorem: Comment," American Economic Review, 71 (December), pp. 1040-1043. 
Leamer, Edward E. and James Levinsohn. 1995. "International Trade Theory: The Evidence," in Gene Grossman and Kenneth Rogoff, eds., Handbook of International Economics, vol. III (Amsterdam: Elsevier Science), pp. 1339-1394.

Levine Ross and David Renelt (1992) “A Sensitivity Analysis of Cross-Country Growth Regressions,” The American Economic Review, 82, pp. 942-963.

Maskus, Keith V. 1985. "A Test of the Heckscher-Ohlin-Vanek Theorem: The Leontief Commonplace," Journal of International Economics, 9 (November), pp. 201-212.

Maskus, Keith V. 1991. "Comparing International Trade Data and Product and National Characteristics Data for the Analysis of Trade Models," in Peter Hooper and J. David Richardson, eds., International Economic Transactions: Issues in Measurement and Empirical Research. (Chicago: The University of Chicago Press), pp. 17-61.

McCallum, John. 1995. "National Borders Matter: Canada-US Regional Trade Patterns," American Economic Review, 85 (June), pp. 615-623.

Melvin, James R. 1968. "Production and Trade with Two Factors and Three Goods," American Economic Review, 58 (December), pp. 1249-1268.

Noland, Marcus. 1993. "The Impact of Industrial Policy on Japan's Trade Specialization," Review of Economics and Statistics, 75, pp. 241-247.

Pritchett, Lant. 1996. "Measuring Outward-Orientation in Developing Countries: Can It Be Done," Journal of Development Economics, 49, pp. 307-335.

Rader, T. 1979. "Factor Price Equalization With More Industries Than Factors," in Jerry R. Green and José A. Scheinkman, eds., General Equilibrium, Growth, and Trade (New York: Academic Press), pp. 347-354.

Reeve, T. 1998. “Explaining Industrial Structure,” Harvard University, mimeo.

Samuelson, Paul A. 1953. "Prices of Factors and Goods in General Equilibrium," Review of Economic Studies, 21, pp. 1-20.

Saxonhouse, Gary R. 1983. "The Micro- and Macroeconomics of Foreign Sales to Japan," in William R. Cline, ed., Trade Policy in the 1980s (Washington: Institute for International Economics), pp. 259-304.

Saxonhouse, Gary R. 1986. "What's Wrong With Japanese Trade Structure?", Pacific Economic Papers, No. 137 (July), pp. 1-36.

Saxonhouse, Gary R. 1989. "Differentiated Products, Economies of Scale, and Access to the Japanese Market," in Robert C. Feenstra, ed., Trade Policies for International Competitiveness (Chicago: University of Chicago Press), pp. 145-174. 
Travis, William P. 1964. The Theory of Trade and Protection. Cambridge: Harvard University Press.

Travis, William P. 1972. "Production, Trade and Protection When There are Many Commodities and Two Factors," American Economic Review, 62, pp. 87-106.

Trefler, Daniel. 1993. "International Factor Price Differences: Leontief was Right!", Journal of Political Economy, 101 (December), pp. 961-987.

Trefler, Daniel. 1995. "The Case of the Missing Trade and Other Mysteries," American Economic Review, 85 (December), pp. 1029-1046.

Vanek, Jaroslav. 1968. "The Factor Proportions Theory: The N-factor Case," Kyklos, 28, pp. 749-755.

$\mathrm{Xu}$, Yingfeng. 1993. "A General Model of Comparative Advantage with Two Factors and a Continuum of Goods," International Economic Review, 34 (2) pp. 365-385. 
Figure 1: Trade Costs and Production Indeterminacy

No Trade Costs

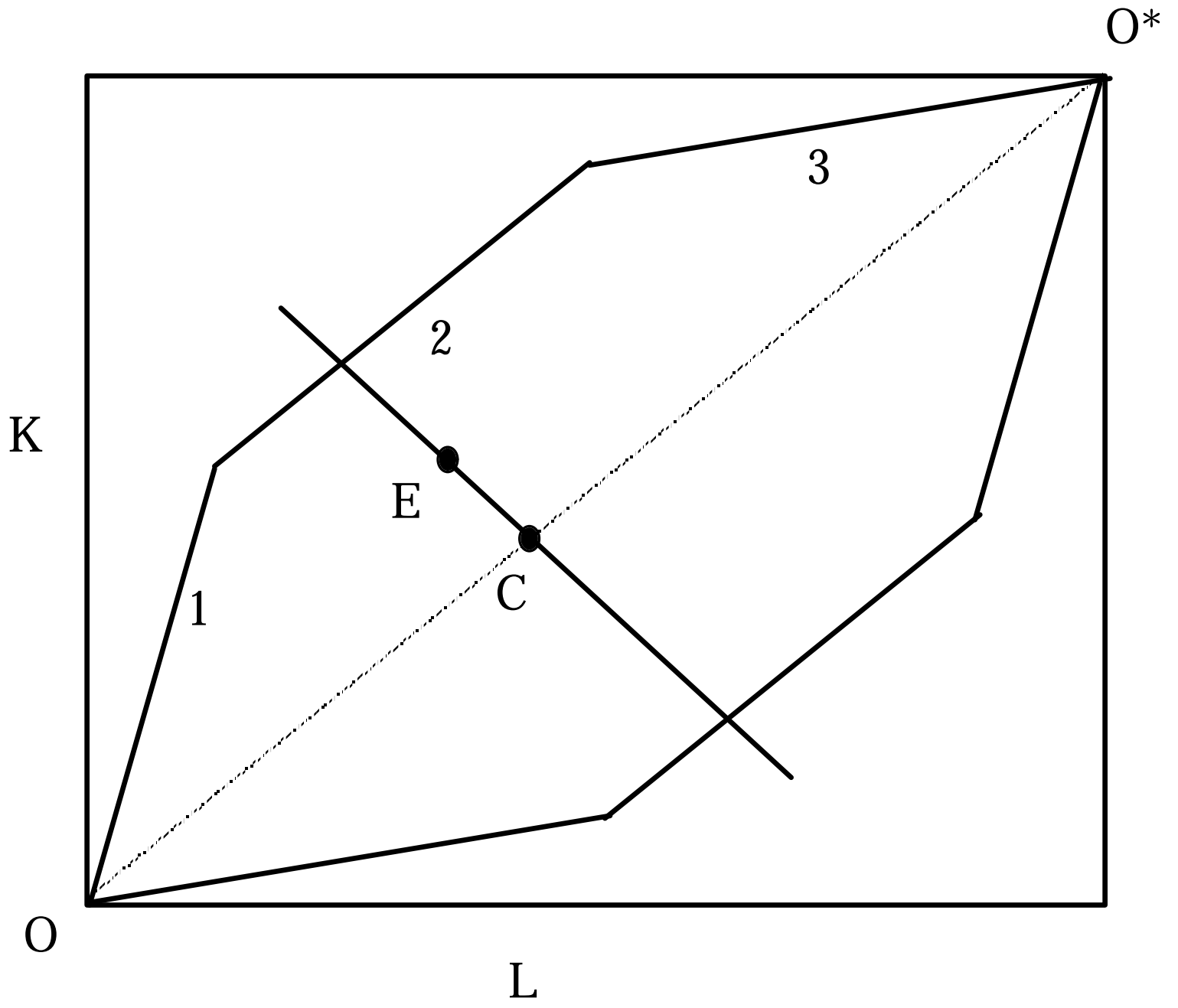


Figure 2: Trade Costs and Production Indeterminacy

Number of Goods Traded at Cost $=\mathbf{N}-\mathbf{F}$

$\mathrm{O} *$

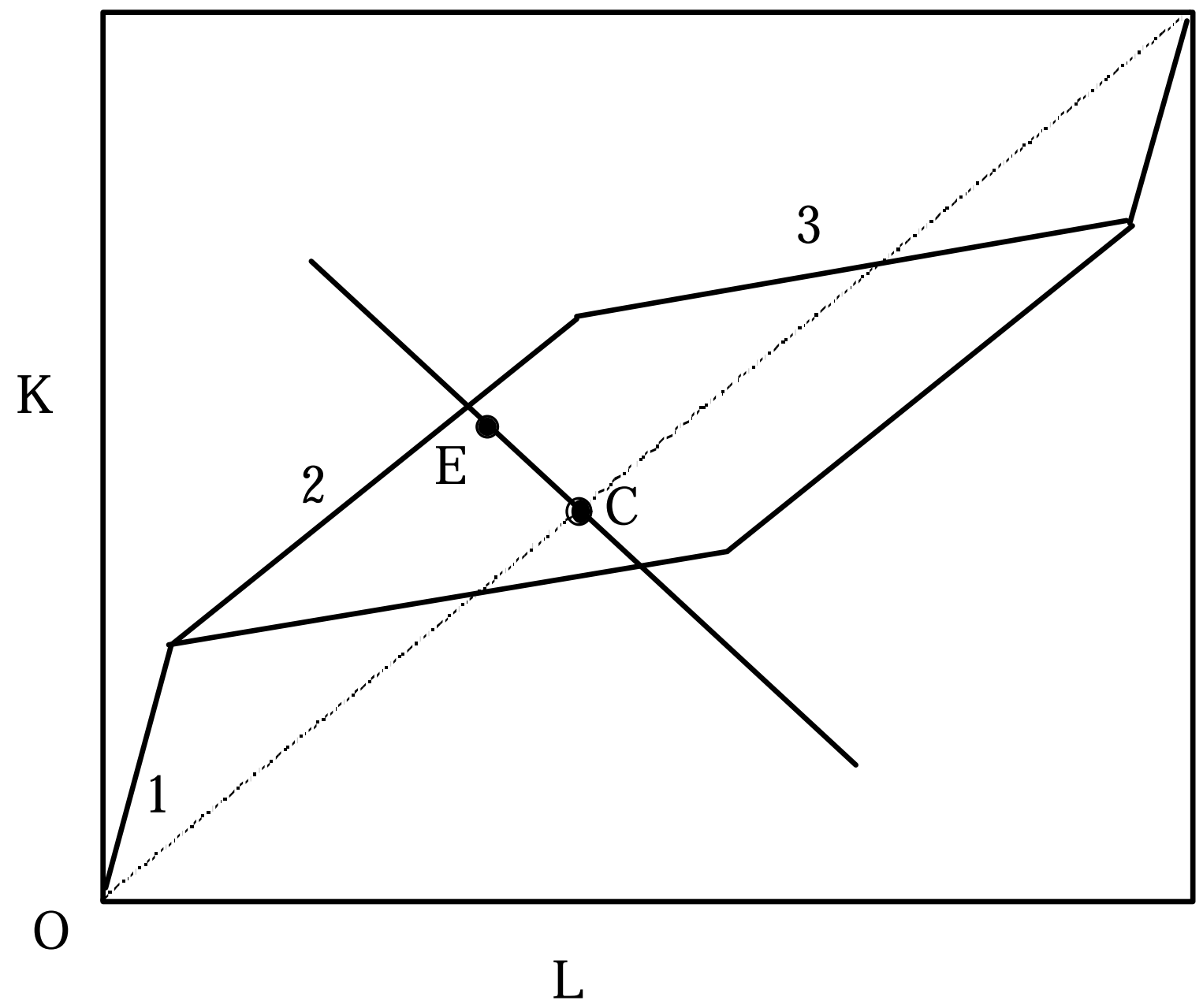


Figure 3: Trade Costs and Production Indeterminacy

Number of Goods Traded at Cost $<$ N - F

$\mathrm{O} *$

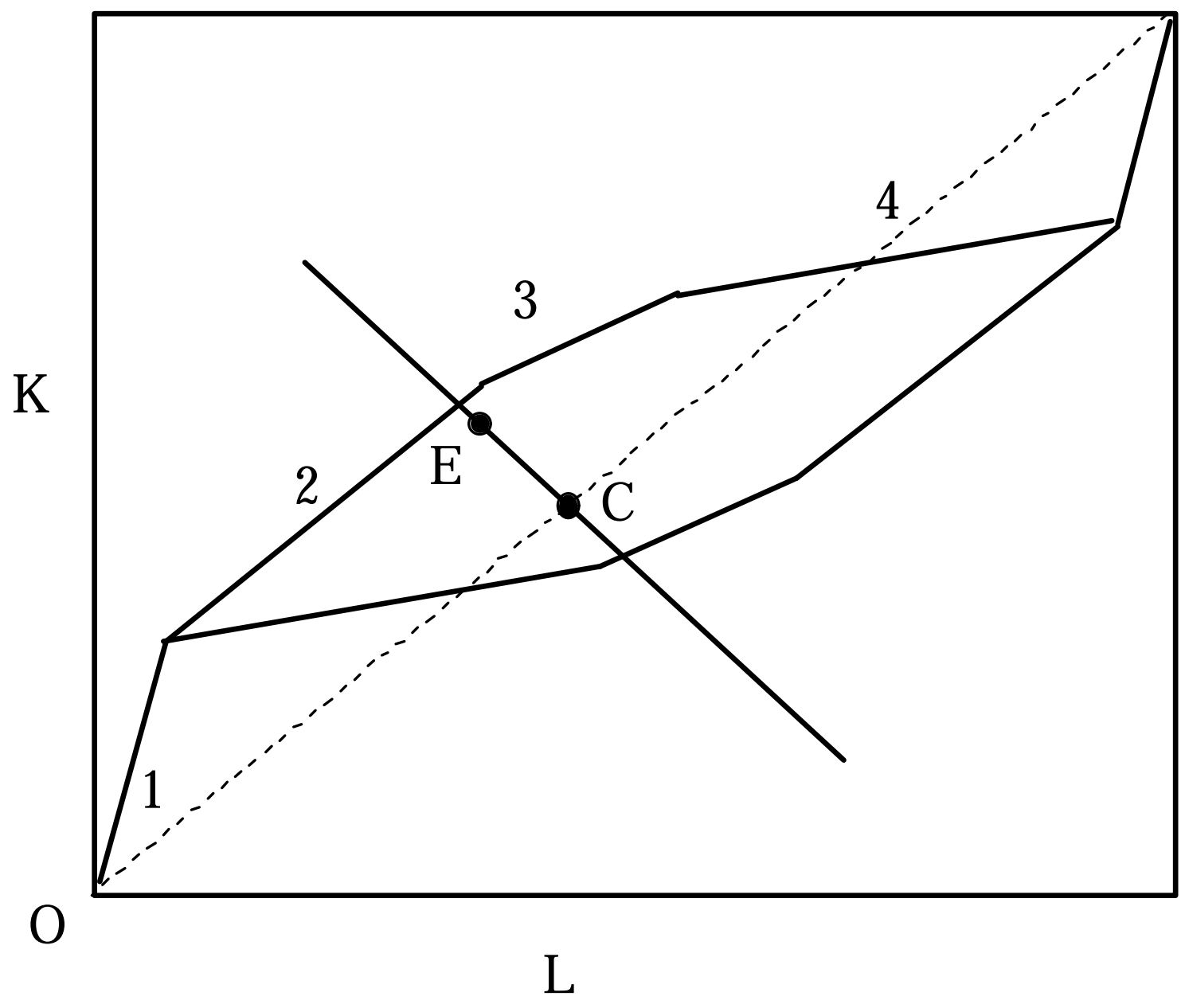


Figure 4: Predicted Versus Actual Endowment

(Unweighted, Endowments expressed as a share of Japan total)

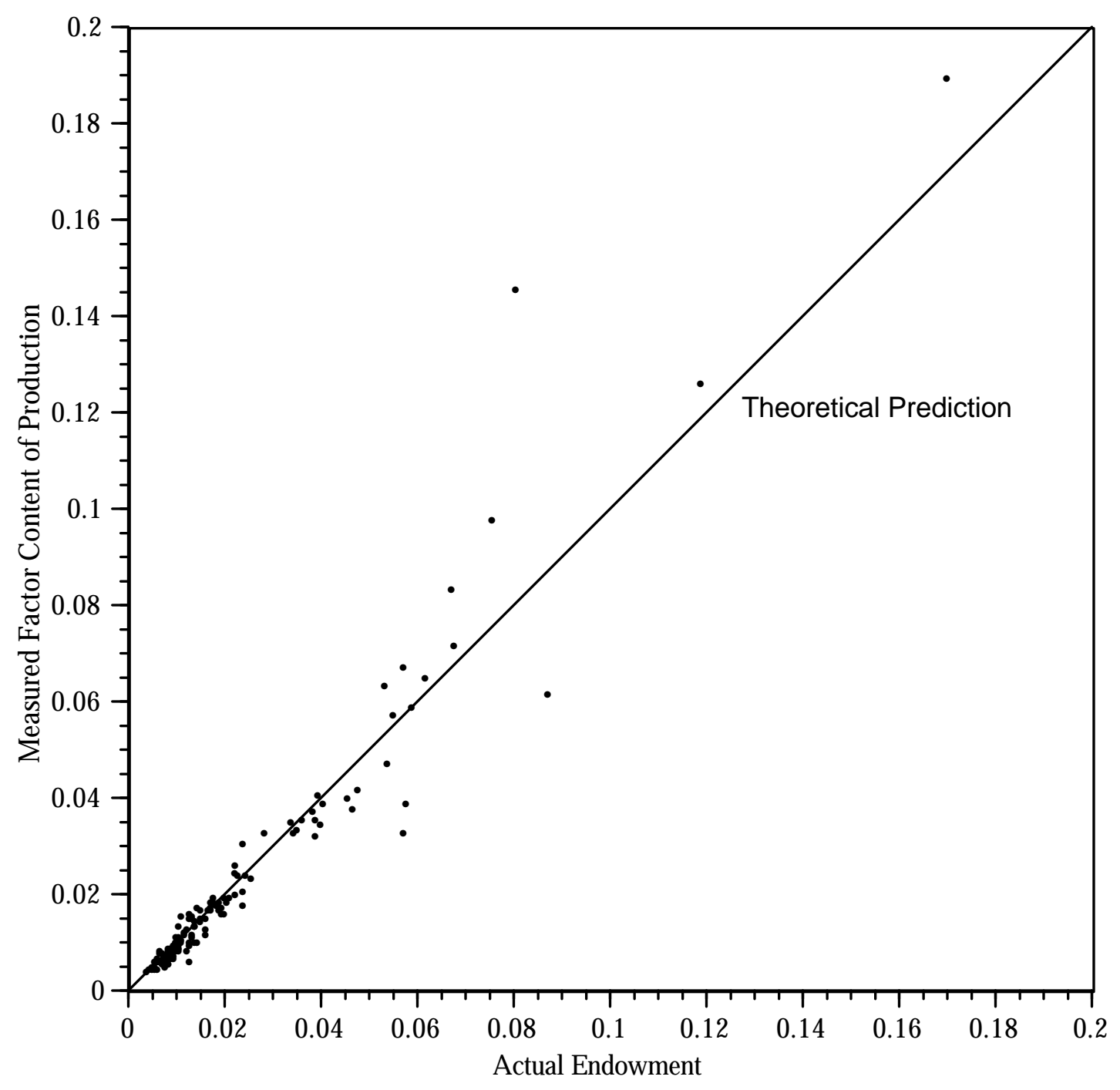


Figure 5: Predicted Versus Actual Endowment

(Weight $=1 /$ SQRT (GDP), Endowments expressed as a

share of Japan total)

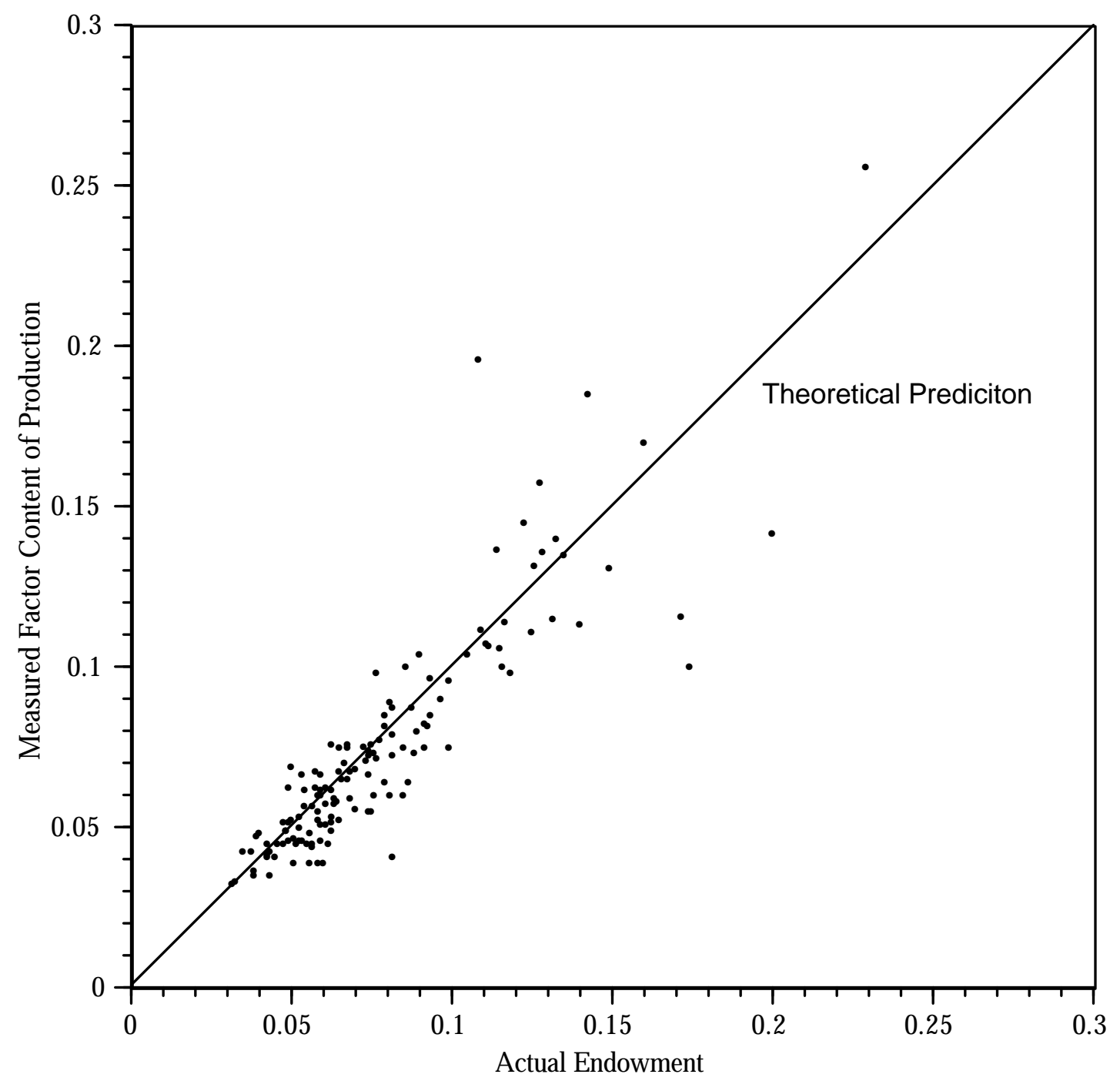


Figure 6: Predicted Versus Actual Output

(3 Factors, Weight $=$ 1/SQRT(GDP),

Output expressed as a share of Japan total)

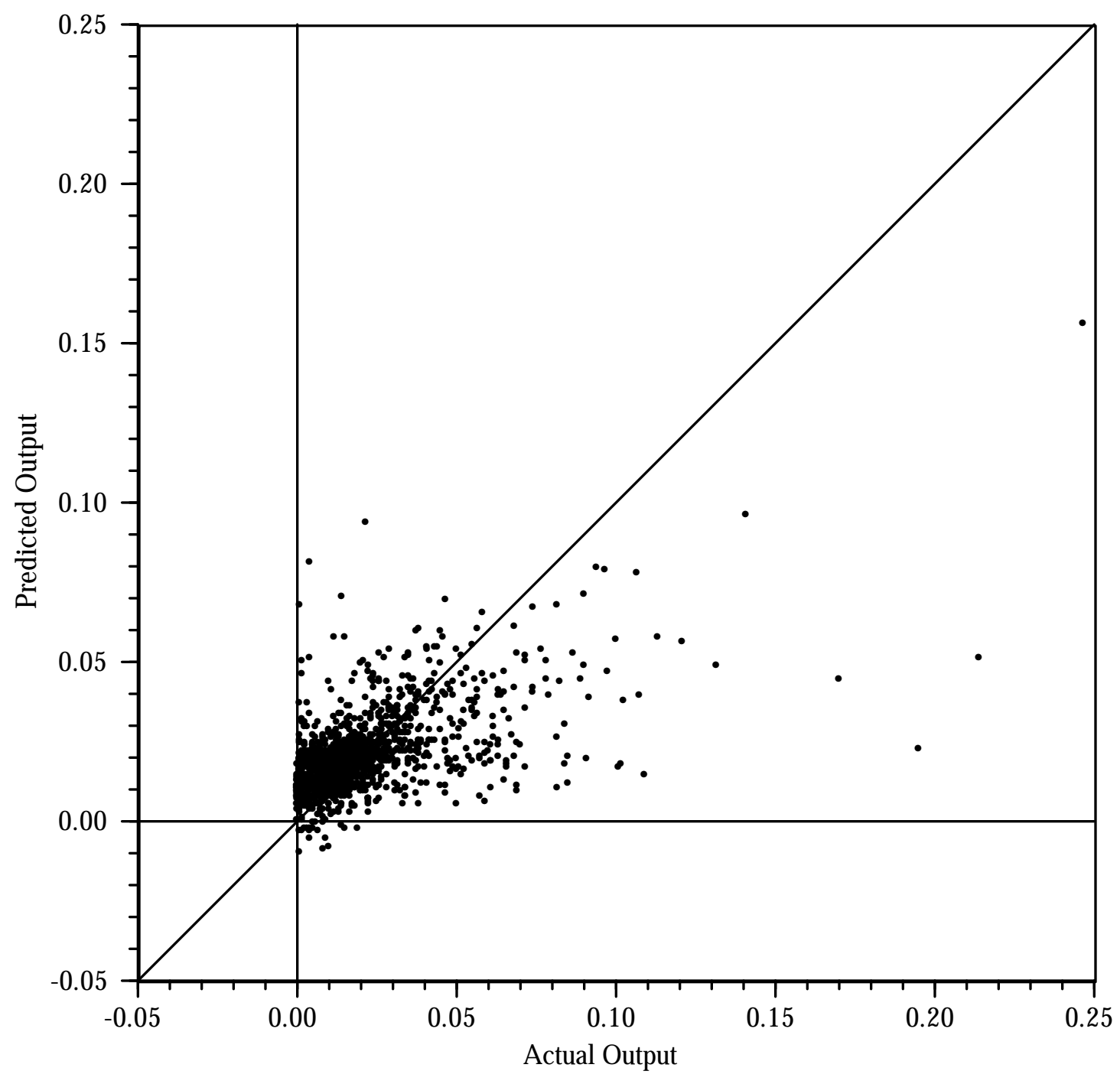




\section{Table 1}

\section{Sample Statistics}

Japanese Regional Data

Mean $\begin{gathered}\text { Standard } \\ \text { Deviation }\end{gathered} \begin{gathered}\text { Coefficient } \\ \text { of Variation }\end{gathered}$ Minimum $\quad$ Maximum

Number of Non-

$\begin{array}{lll}1349475 & 1088710 & 0.81\end{array}$

$372125 \quad 5098118$

College Graduates

Number of College

Graduates

Capital Stock

$\begin{array}{rrrrr}363057 & 500328 & 1.38 & 62628 & 2898431 \\ 6433723 & 6428413 & 1.00 & 1469625 & 35838100\end{array}$

Number of 4-year

231057

342366

1.48

$36324 \quad 1980297$

College Graduates

$$
131999
$$

158831

1.20

26304

918127

College Graduates

$$
838674
$$

752495

0.90

231544

3697818

School Graduates

$$
510799
$$

352666

0.69

$140580 \quad 1491256$

than High School

$$
1731
$$

$$
2311
$$

1.33

453

16487

Land

Mountain and Forest

1803

1784

0.99

215

11873

Land

GDP

6833167

9082048

1.33

$1327762 \quad 55100600$ 


\title{
Table 1 (Continued)
}

\author{
International Data
}

\begin{tabular}{|c|c|c|c|c|c|}
\hline & Mean & Standard Dev & $\begin{array}{l}\text { oefficient } \\
\text { Variation }\end{array}$ & Minimum & Maximum \\
\hline $\begin{array}{l}\text { Number of Non } \\
\text { College Graduates }\end{array}$ & 14951523 & 19608955 & 1.31 & 992420 & 79190398 \\
\hline $\begin{array}{l}\text { Number of College } \\
\text { Graduates }\end{array}$ & 3306250 & 8048680 & 2.43 & 73008 & 37609602 \\
\hline Capital Stock & 753060000 & 1303170000 & 1.73 & 46403000 & 5714800000 \\
\hline Arable Land & 18860 & 40437 & 2.14 & 771 & 189799 \\
\hline Mineral Output & 146354 & 409690 & 2.80 & 22 & 1935810 \\
\hline GDP & 459701000 & 855778000 & 1.86 & 25541100 & 3962220000 \\
\hline
\end{tabular}

All nominal variables in the regional data set are expressed as millions of yen.

All nominal variables in the international data set are expressed as thousands of dollars. Land is in square kilometers in the Japanese data and in thousands of hectares in the international data. 
Table 2

Coefficient of Variation in Regional Output Data

\begin{tabular}{|c|c|c|c|}
\hline Hokkaido & 1.70 & Shiga & 1.32 \\
\hline Aomori & 1.83 & Kyoto & 1.08 \\
\hline Iwate & 1.42 & Osaka & 0.91 \\
\hline Miyagi & 1.45 & Hyogo & 1.05 \\
\hline Akita & 1.36 & Nara & 1.34 \\
\hline Yamagata & 1.57 & Wakayama & 1.57 \\
\hline Fukushima & 1.43 & Tottori & 1.70 \\
\hline Ibaraki & 1.12 & Shimane & 0.99 \\
\hline Tochigi & 1.32 & Okayama & 1.11 \\
\hline Gumma & 1.54 & Hiroshima & 1.41 \\
\hline Saitama & 1.07 & Yamaguchi & 1.35 \\
\hline Chiba & 1.23 & Tokushima & 1.22 \\
\hline Tokyo & 1.25 & Kagawa & 0.96 \\
\hline Kanagawa & 1.34 & Ehime & 1.07 \\
\hline Niigata & 0.94 & Kochi & 1.04 \\
\hline Toyama & 1.07 & Fukuoka & 0.97 \\
\hline Ishikawa & 1.52 & Saga & 1.31 \\
\hline Fukui & 1.50 & Nagasaki & 1.65 \\
\hline Yamanashi & 1.76 & Kumamoto & 1.17 \\
\hline Nagano & 1.68 & Oita & 1.12 \\
\hline Gifu & 0.88 & Miyazaki & 1.60 \\
\hline Shizuoka & 1.18 & Kagoshima & 2.36 \\
\hline Aichi & 1.70 & Okinawa & 1.96 \\
\hline Mie & 1.11 & Total Average & 1.35 \\
\hline
\end{tabular}


Table 3

Cofficients of Variation for Regional Output or International Production Data

\begin{tabular}{|c|c|c|c|}
\hline Industry & $\begin{array}{c}\text { Regional } \\
\text { Data }\end{array}$ & $\begin{array}{c}\text { International } \\
\text { Data }\end{array}$ & $\begin{array}{c}\text { Int'l Data } \\
\text { w/o US \& } \\
\text { New Zealand }\end{array}$ \\
\hline Agriculture/Fishery & 0.75 & & \\
\hline Mining & 1.54 & & \\
\hline Construction & 0.87 & & \\
\hline Processed Food & 0.81 & 1.94 & 1.29 \\
\hline Textiles & 1.18 & 1.88 & 1.38 \\
\hline Apparel & 0.94 & 2.10 & 1.30 \\
\hline Lumber and Wood & 0.67 & 1.94 & 1.36 \\
\hline Furniture & 1.04 & 1.65 & 1.23 \\
\hline Paper \& Pulp & 1.08 & 2.37 & 1.37 \\
\hline Publishing & 2.64 & 2.33 & 1.43 \\
\hline Chemicals & 1.14 & 2.13 & 1.52 \\
\hline Petroleum \& Coal & 1.57 & 2.56 & 1.48 \\
\hline Rubber & 1.22 & 2.22 & 1.98 \\
\hline Leather \& Footwear & 1.98 & 1.39 & 1.22 \\
\hline Ceramics \& Glass & 0.83 & 1.81 & 1.61 \\
\hline Iron \& Steel & 1.34 & 1.81 & 1.74 \\
\hline Non-Ferrous Metals & 1.04 & 2.20 & 1.36 \\
\hline Metal Products & 1.14 & 2.25 & 1.79 \\
\hline General Machinery & 1.11 & 2.22 & 1.75 \\
\hline Electrical Machinery & 1.07 & 2.26 & 2.23 \\
\hline Transport Machinery & 1.91 & 2.21 & 1.83 \\
\hline Precision Instrument & 1.51 & 2.58 & 2.54 \\
\hline Other Manufacturing & 1.08 & & \\
\hline Transportation/Communication & 1.47 & & \\
\hline Electricity/Gas/Water & 0.93 & & \\
\hline Wholesale/Retail & 1.56 & & \\
\hline Finance/Insurance/Real Estate & 1.40 & & \\
\hline Other Services & 1.60 & & \\
\hline Public Administration & 0.92 & & \\
\hline Total Average & 1.25 & 2.10 & 1.60 \\
\hline
\end{tabular}


Table 4

\section{Coefficients of Variation for Production by Country}

\begin{tabular}{|lr|}
\hline Australia & 0.88 \\
Austria & 0.79 \\
Benelus & 0.87 \\
Canada & 0.86 \\
Denmark & 1.52 \\
Finland & 0.97 \\
France & 0.93 \\
Germany & 0.86 \\
Greece & 1.06 \\
Ireland & 1.74 \\
Italy & 0.74 \\
Japan & 0.75 \\
Netherlands & 1.34 \\
New Zealand & 1.21 \\
Norway & 0.98 \\
Portugal & 0.89 \\
Spain & 0.88 \\
Sweden & 0.77 \\
Turkey & 1.17 \\
United Kingdom & 0.88 \\
USA & 0.80 \\
Yugoslavia & 0.65 \\
\hline Average & 0.98 \\
\hline
\end{tabular}


Table 5

Deviations from the HOV Model of Production

$$
\left|\frac{\mathrm{BX}}{\mathrm{V}}-1\right|
$$

\section{Prefectural Averages}

\begin{tabular}{|lr|}
\hline Hokkaido & $9 \%$ \\
Aomori & $17 \%$ \\
Iwate & $13 \%$ \\
Miyagi & $7 \%$ \\
Akita & $16 \%$ \\
Yamagata & $14 \%$ \\
Fukushima & $18 \%$ \\
Ibaraki & $12 \%$ \\
Tochigi & $14 \%$ \\
Gumma & $11 \%$ \\
Saitama & $20 \%$ \\
Chiba & $21 \%$ \\
Tokyo & $33 \%$ \\
Kanagawa & $11 \%$ \\
Niigata & $19 \%$ \\
Toyama & $7 \%$ \\
Ishikawa & $12 \%$ \\
Fukui & $14 \%$ \\
Yamanashi & $10 \%$ \\
Nagano & $14 \%$ \\
Gifu & $6 \%$ \\
Shizuoka & $16 \%$ \\
Aichi & $15 \%$ \\
Mie & $11 \%$ \\
\hline
\end{tabular}

\begin{tabular}{|lr|}
\hline Shiga & $7 \%$ \\
Kyoto & $5 \%$ \\
Osaka & $20 \%$ \\
Hyogo & $5 \%$ \\
Nara & $31 \%$ \\
Wakayama & $11 \%$ \\
Tottori & $9 \%$ \\
Shimane & $17 \%$ \\
Okayama & $6 \%$ \\
Hiroshima & $6 \%$ \\
Yamaguchi & $8 \%$ \\
Tokushima & $14 \%$ \\
Kagawa & $10 \%$ \\
Ehime & $7 \%$ \\
Kochi & $10 \%$ \\
Fukuoka & $6 \%$ \\
Saga & $12 \%$ \\
Nagasaki & $11 \%$ \\
Kumamoto & $8 \%$ \\
Oita & $8 \%$ \\
Miyazaki & $11 \%$ \\
Kagoshima & $11 \%$ \\
Okinawa & $27 \%$ \\
\hline Total Average & $13 \%$ \\
\hline
\end{tabular}

Factor Averages

\begin{tabular}{|lr|}
\hline Non-college & $17 \%$ \\
College & $14 \%$ \\
Capital & $7 \%$ \\
\hline Total Average & $13 \%$ \\
\hline
\end{tabular}


Table 6

Correlation Between Endowment Deviations and Factor Intensity of Production

\begin{tabular}{lccc}
\hline Tests & Noncollege & College & Capital \\
\hline I. Sign Tests & & & \\
$\left(\mathrm{V}^{\mathrm{i}}-\mathrm{Vj}\right) \mathrm{T} \mathrm{B}\left(\mathrm{X}^{\mathrm{i}}-\mathrm{Xj}\right)$ Negative & 61 & 75 & 32 \\
$\%$ Negative & 5.64 & 6.94 & 2.96 \\
\hline II. Within-Factor Correlations & & & \\
Raw Correlation & 0.96 & 0.99 & 0.99 \\
Rank Correlation & 0.98 & 0.96 & \\
III. Cross-Factor Correlations & & & \\
Average Raw Correlation $=0.84$ & & & \\
Average Rank Correlation $=0.78$ & & & \\
\hline
\end{tabular}


Table 7: Three Factor Model, Weight $=1 / \sqrt{\mathrm{GDP}}$

(Standard Errors in Parentheses, Constant Not Reported)

\begin{tabular}{|c|c|c|c|c|c|}
\hline Dependent Variable & Non-College & College & Capital & $\begin{array}{c}\text { Number of } \\
\text { Positive } \\
\text { Observations }\end{array}$ & $\mathrm{R}^{2}$ \\
\hline Agriculture/Fishery & $\begin{array}{c}0.375 \\
(0.152)\end{array}$ & $\begin{array}{c}-1.548 \\
(0.265)\end{array}$ & $\begin{array}{c}0.060 \\
(0.036)\end{array}$ & 47 & 0.511 \\
\hline Mining & $\begin{array}{l}-0.039 \\
(0.024)\end{array}$ & $\begin{array}{l}-0.122 \\
(0.042)\end{array}$ & $\begin{array}{c}0.022 \\
(0.006)\end{array}$ & 47 & 0.290 \\
\hline Construction & $\begin{array}{c}0.157 \\
(0.123)\end{array}$ & $\begin{array}{c}-0.022 \\
(0.215)\end{array}$ & $\begin{array}{c}0.160 \\
(0.029)\end{array}$ & 47 & 0.882 \\
\hline Processed Food & $\begin{array}{c}0.647 \\
(0.192)\end{array}$ & $\begin{array}{l}-0.524 \\
(0.334)\end{array}$ & $\begin{array}{c}0.019 \\
(0.046)\end{array}$ & 47 & 0.566 \\
\hline Textiles & $\begin{array}{c}0.049 \\
(0.194)\end{array}$ & $\begin{array}{c}-0.124 \\
(0.338)\end{array}$ & $\begin{array}{c}0.020 \\
(0.046)\end{array}$ & 47 & 0.006 \\
\hline Apparel & $\begin{array}{c}0.075 \\
(0.043)\end{array}$ & $\begin{array}{c}0.016 \\
(0.075)\end{array}$ & $\begin{array}{c}-0.009 \\
(0.010)\end{array}$ & 47 & 0.014 \\
\hline Lumber and Wood & $\begin{array}{c}0.048 \\
(0.041)\end{array}$ & $\begin{array}{c}-0.247 \\
(0.072)\end{array}$ & $\begin{array}{c}0.016 \\
(0.010)\end{array}$ & 47 & 0.226 \\
\hline Furniture & $\begin{array}{c}0.052 \\
(0.026)\end{array}$ & $\begin{array}{c}-0.001 \\
(0.045)\end{array}$ & $\begin{array}{c}-0.003 \\
(0.006)\end{array}$ & 47 & 0.223 \\
\hline Paper \& Pulp & $\begin{array}{c}0.297 \\
(0.108)\end{array}$ & $\begin{array}{c}-0.059 \\
(0.187)\end{array}$ & $\begin{array}{c}-0.028 \\
(0.026)\end{array}$ & 47 & 0.236 \\
\hline Publishing & $\begin{array}{l}-0.475 \\
(0.122)\end{array}$ & $\begin{array}{c}0.677 \\
(0.213)\end{array}$ & $\begin{array}{c}0.094 \\
(0.029)\end{array}$ & 47 & 0.629 \\
\hline Chemicals & $\begin{array}{c}0.585 \\
(0.324)\end{array}$ & $\begin{array}{c}1.152 \\
(0.563)\end{array}$ & $\begin{array}{c}-0.102 \\
(0.077)\end{array}$ & 47 & 0.282 \\
\hline Petroleum \& Coal & $\begin{array}{l}-0.071 \\
(0.360)\end{array}$ & $\begin{array}{c}0.837 \\
(0.627)\end{array}$ & $\begin{array}{c}0.014 \\
(0.085)\end{array}$ & 47 & 0.123 \\
\hline Rubber & $\begin{array}{c}0.068 \\
(0.047)\end{array}$ & $\begin{array}{c}0.064 \\
(0.081)\end{array}$ & $\begin{array}{l}-0.005 \\
(0.011)\end{array}$ & 45 & 0.250 \\
\hline Leather \& Footwear & $\begin{array}{c}-0.004 \\
(0.020)\end{array}$ & $\begin{array}{c}0.102 \\
(0.035)\end{array}$ & $\begin{array}{c}-0.001 \\
(0.005)\end{array}$ & 44 & 0.360 \\
\hline Ceramics \& Glass & $\begin{array}{c}0.198 \\
(0.110)\end{array}$ & $\begin{array}{c}-0.065 \\
(0.192)\end{array}$ & $\begin{array}{c}-0.006 \\
(0.026)\end{array}$ & 47 & 0.105 \\
\hline Iron \& Steel & $\begin{array}{c}0.189 \\
(0.315)\end{array}$ & $\begin{array}{c}0.488 \\
(0.548)\end{array}$ & $\begin{array}{c}0.014 \\
(0.075)\end{array}$ & 47 & 0.264 \\
\hline Non-Ferrous Metals & $\begin{array}{c}0.299 \\
(0.076)\end{array}$ & $\begin{array}{c}0.092 \\
(0.132)\end{array}$ & $\begin{array}{c}-0.030 \\
(0.018)\end{array}$ & 43 & 0.278 \\
\hline
\end{tabular}


Table 7 (Continued)

\begin{tabular}{|c|c|c|c|c|c|}
\hline Dependent Variable & Non-College & College & Capital & $\begin{array}{l}\text { Number of } \\
\text { Positive } \\
\text { Observations }\end{array}$ & $\mathrm{R}^{2}$ \\
\hline Metal Products & $\begin{array}{c}0.335 \\
(0.167)\end{array}$ & $\begin{array}{c}0.438 \\
(0.291)\end{array}$ & $\begin{array}{c}-0.034 \\
(0.040)\end{array}$ & 47 & 0.393 \\
\hline General Machinery & $\begin{array}{c}0.825 \\
(0.324)\end{array}$ & $\begin{array}{c}1.238 \\
(0.565)\end{array}$ & $\begin{array}{l}-0.115 \\
(0.077)\end{array}$ & 47 & 0.446 \\
\hline Electrical Machinery & $\begin{array}{c}1.207 \\
(0.478)\end{array}$ & $\begin{array}{c}1.774 \\
(0.831)\end{array}$ & $\begin{array}{l}-0.201 \\
(0.113)\end{array}$ & 47 & 0.331 \\
\hline Transport Machinery & $\begin{array}{c}1.125 \\
(0.815)\end{array}$ & $\begin{array}{c}0.470 \\
(1.419)\end{array}$ & $\begin{array}{l}-0.064 \\
(0.194)\end{array}$ & 47 & 0.251 \\
\hline Precision Instrument & $\begin{array}{c}0.049 \\
(0.092)\end{array}$ & $\begin{array}{c}0.116 \\
(0.161)\end{array}$ & $\begin{array}{r}-0.0006 \\
(0.022)\end{array}$ & 47 & 0.140 \\
\hline Other Manufacturing & $\begin{array}{c}0.526 \\
(0.147)\end{array}$ & $\begin{array}{c}0.601 \\
(0.256)\end{array}$ & $\begin{array}{c}-0.091 \\
(0.035)\end{array}$ & 47 & 0.429 \\
\hline Transport \& Com. & $\begin{array}{l}-0.682 \\
(0.137)\end{array}$ & $\begin{array}{c}0.904 \\
(0.238)\end{array}$ & $\begin{array}{c}0.205 \\
(0.033)\end{array}$ & 47 & 0.852 \\
\hline Electricity/Gas/Water & $\begin{array}{l}-0.043 \\
(0.159)\end{array}$ & $\begin{array}{c}-0.131 \\
(0.276)\end{array}$ & $\begin{array}{c}0.079 \\
(0.038)\end{array}$ & 47 & 0.338 \\
\hline Wholesale/Retail & $\begin{array}{l}-1.219 \\
(0.398)\end{array}$ & $\begin{array}{c}0.975 \\
(0.694)\end{array}$ & $\begin{array}{c}0.433 \\
(0.095)\end{array}$ & 47 & 0.723 \\
\hline Finance/Ins./Real Est. & $\begin{array}{l}-0.626 \\
(0.223)\end{array}$ & $\begin{array}{c}2.082 \\
(0.389)\end{array}$ & $\begin{array}{c}0.214 \\
(0.053)\end{array}$ & 47 & 0.857 \\
\hline Other Services & $\begin{array}{l}-2.078 \\
(0.438)\end{array}$ & $\begin{array}{c}2.141 \\
(0.763)\end{array}$ & $\begin{array}{c}0.600 \\
(0.104)\end{array}$ & 47 & 0.788 \\
\hline Public Administration & $\begin{array}{l}-0.096 \\
(0.095)\end{array}$ & $\begin{array}{l}-0.170 \\
(0.166)\end{array}$ & $\begin{array}{c}0.141 \\
(0.023)\end{array}$ & 47 & 0.796 \\
\hline
\end{tabular}


Table 8

Errors in Prediction of Output

$\left|\frac{\Omega \mathrm{V}}{\mathrm{X}}-1\right|$

(Three Factors, 1/SQRT(GDP) Weighting)

\section{Prefectural Averages}

\begin{tabular}{|lr|}
\hline Hokkaido & $503 \%$ \\
Aomori & $575 \%$ \\
Iwate & $303 \%$ \\
Miyagi & $115 \%$ \\
Akita & $161 \%$ \\
Yamagata & $167 \%$ \\
Fukushima & $75 \%$ \\
Ibaraki & $50 \%$ \\
Tochigi & $90 \%$ \\
Gumma & $116 \%$ \\
Saitama & $122 \%$ \\
Chiba & $124 \%$ \\
Tokyo & $271 \%$ \\
Kanagawa & $156 \%$ \\
Niigata & $110 \%$ \\
Toyama & $70 \%$ \\
Ishikawa & $332 \%$ \\
Fukui & $241 \%$ \\
Yamanashi & $270 \%$ \\
Nagano & $183 \%$ \\
Gifu & $165 \%$ \\
Shizuoka & $60 \%$ \\
Aichi & $49 \%$ \\
Mie & $53 \%$ \\
\hline
\end{tabular}

\begin{tabular}{|lr|}
\hline Shiga & $120 \%$ \\
Kyoto & $287 \%$ \\
Osaka & $112 \%$ \\
Hyogo & $42 \%$ \\
Nara & $226 \%$ \\
Wakayama & $160 \%$ \\
Tottori & $423 \%$ \\
Shimane & $279 \%$ \\
Okayama & $50 \%$ \\
Hiroshima & $158 \%$ \\
Yamaguchi & $187 \%$ \\
Tokushima & $426 \%$ \\
Kagawa & $50 \%$ \\
Ehime & $279 \%$ \\
Kochi & $469 \%$ \\
Fukuoka & $151 \%$ \\
Saga & $384 \%$ \\
Nagasaki & $2131 \%$ \\
Kumamoto & $376 \%$ \\
Oita & $68 \%$ \\
Miyazaki & $523 \%$ \\
Kagoshima & $1007 \%$ \\
Okinawa & $2120 \%$ \\
\hline Total Average & $304 \%$ \\
\hline
\end{tabular}


Table 8 (Continued)

\section{Industry Averages}

\begin{tabular}{|lr|}
\hline Agriculture/Fishery & $56 \%$ \\
Mining & $120 \%$ \\
Construction & $9 \%$ \\
Processed Food & $37 \%$ \\
Textiles & $294 \%$ \\
Apparel & $93 \%$ \\
Lumber and Wood & $45 \%$ \\
Furniture & $102 \%$ \\
Paper \& Pulp & $117 \%$ \\
Publishing & $91 \%$ \\
Chemicals & $406 \%$ \\
Petroleum \& Coal & $2165 \%$ \\
Rubber & $419 \%$ \\
Leather \& Footwear & $539 \%$ \\
Ceramics \& Glass & $49 \%$ \\
Iron \& Steel & $312 \%$ \\
Non-Ferrous Metals & $945 \%$ \\
Metal Products & $82 \%$ \\
General Machinery & $336 \%$ \\
Electrical Machinery & $516 \%$ \\
Transport Machinery & $556 \%$ \\
Precision Instrument & $1266 \%$ \\
Other Manufacturing & $141 \%$ \\
Transportation/Communication & $20 \%$ \\
Electricity/Gas/Water & $38 \%$ \\
Wholesale/Retail & $26 \%$ \\
Finance/Insurance/Real Estate & $15 \%$ \\
Other Services & $23 \%$ \\
Public Administration & $12 \%$ \\
\hline Total Average & $304 \%$ \\
\hline
\end{tabular}




\section{Table 9a}

Errors in Prediction of Output

$$
\left|\frac{\Omega V}{X}-1\right|
$$

(Five Factors, 1/SQRT(GDP) Weighting)

\section{Prefectural Average Errors}

\begin{tabular}{|lr|}
\hline Hokkaido & $243 \%$ \\
Aomori & $369 \%$ \\
Iwate & $239 \%$ \\
Miyagi & $136 \%$ \\
Akita & $78 \%$ \\
Yamagata & $115 \%$ \\
Fukushima & $78 \%$ \\
Ibaraki & $51 \%$ \\
Tochigi & $78 \%$ \\
Gumma & $93 \%$ \\
Saitama & $108 \%$ \\
Chiba & $75 \%$ \\
Tokyo & $273 \%$ \\
Kanagawa & $158 \%$ \\
Niigata & $144 \%$ \\
Toyama & $76 \%$ \\
Ishikawa & $353 \%$ \\
Fukui & $340 \%$ \\
Yamanashi & $231 \%$ \\
Nagano & $196 \%$ \\
Gifu & $224 \%$ \\
Shizuoka & $63 \%$ \\
Aichi & $38 \%$ \\
Mie & $55 \%$ \\
\hline
\end{tabular}

\begin{tabular}{|lr|}
\hline Shiga & $109 \%$ \\
Kyoto & $282 \%$ \\
Osaka & $86 \%$ \\
Hyogo & $46 \%$ \\
Nara & $233 \%$ \\
Wakayama & $161 \%$ \\
Tottori & $344 \%$ \\
Shimane & $454 \%$ \\
Okayama & $51 \%$ \\
Hiroshima & $176 \%$ \\
Yamaguchi & $206 \%$ \\
Tokushima & $463 \%$ \\
Kagawa & $52 \%$ \\
Ehime & $286 \%$ \\
Kochi & $776 \%$ \\
Fukuoka & $184 \%$ \\
Saga & $338 \%$ \\
Nagasaki & $2253 \%$ \\
Kumamoto & $345 \%$ \\
Oita & $62 \%$ \\
Miyazaki & $549 \%$ \\
Kagoshima & $866 \%$ \\
Okinawa & $2314 \%$ \\
Total Average & $305 \%$ \\
\hline
\end{tabular}


Table 9a (Continued)

Industry Average Errors and Regression $\mathbf{R}^{2}$ 's

\begin{tabular}{|lr|c|}
\hline Industry & \multicolumn{1}{|c|}{ Error } & $\mathrm{R}^{2}$ \\
\hline Agriculture/Fishery & $35 \%$ & 0.780 \\
Mining & $118 \%$ & 0.349 \\
Construction & $9 \%$ & 0.910 \\
Processed Food & $35 \%$ & 0.584 \\
Textiles & $248 \%$ & 0.207 \\
Apparel & $79 \%$ & 0.172 \\
Lumber and Wood & $39 \%$ & 0.346 \\
Furniture & $95 \%$ & 0.365 \\
Paper \& Pulp & $108 \%$ & 0.252 \\
Publishing & $96 \%$ & 0.637 \\
Chemicals & $334 \%$ & 0.363 \\
Petroleum \& Coal & $2244 \%$ & 0.142 \\
Rubber & $398 \%$ & 0.375 \\
Leather \& Footwear & $533 \%$ & 0.361 \\
Ceramics \& Glass & $47 \%$ & 0.173 \\
Iron \& Steel & $298 \%$ & 0.329 \\
Non-Ferrous Metals & $1117 \%$ & 0.394 \\
Metal Products & $73 \%$ & 0.545 \\
General Machinery & $294 \%$ & 0.605 \\
Electrical Machinery & $540 \%$ & 0.364 \\
Transport Machinery & $569 \%$ & 0.405 \\
Precision Instrument & $1278 \%$ & 0.146 \\
Other Manufacturing & $133 \%$ & 0.553 \\
Transportation/Communication & $21 \%$ & 0.859 \\
Electricity/Gas/Water & $35 \%$ & 0.389 \\
Wholesale/Retail & $28 \%$ & 0.767 \\
Finance/Insurance/Real Estate & $15 \%$ & 0.860 \\
Other Services & $24 \%$ & 0.791 \\
Public Administration & $11 \%$ & 0.852 \\
\hline Total Average & $305 \%$ & 0.478 \\
\hline
\end{tabular}


Table 9b

Errors in Prediction of Output

$\left|\frac{\Omega V}{X}-1\right|$

(Seven Factors, 1/SQRT(GDP) Weighting)

\section{Prefectural Average Errors}

\begin{tabular}{|lr|}
\hline Hokkaido & $279 \%$ \\
Aomori & $432 \%$ \\
Iwate & $180 \%$ \\
Miyagi & $150 \%$ \\
Akita & $123 \%$ \\
Yamagata & $193 \%$ \\
Fukushima & $79 \%$ \\
Ibaraki & $48 \%$ \\
Tochigi & $106 \%$ \\
Gumma & $39 \%$ \\
Saitama & $58 \%$ \\
Chiba & $55 \%$ \\
Tokyo & $190 \%$ \\
Kanagawa & $153 \%$ \\
Niigata & $143 \%$ \\
Toyama & $86 \%$ \\
Ishikawa & $247 \%$ \\
Fukui & $448 \%$ \\
Yamanashi & $179 \%$ \\
Nagano & $166 \%$ \\
Gifu & $86 \%$ \\
Shizuoka & $51 \%$ \\
Aichi & $41 \%$ \\
Mie & $50 \%$ \\
\hline
\end{tabular}

\begin{tabular}{|lr|}
\hline Shiga & $65 \%$ \\
Kyoto & $209 \%$ \\
Osaka & $78 \%$ \\
Hyogo & $45 \%$ \\
Nara & $238 \%$ \\
Wakayama & $158 \%$ \\
Tottori & $771 \%$ \\
Shimane & $653 \%$ \\
Okayama & $51 \%$ \\
Hiroshima & $126 \%$ \\
Yamaguchi & $206 \%$ \\
Tokushima & $347 \%$ \\
Kagawa & $62 \%$ \\
Ehime & $295 \%$ \\
Kochi & $760 \%$ \\
Fukuoka & $192 \%$ \\
Saga & $403 \%$ \\
Nagasaki & $1985 \%$ \\
Kumamoto & $284 \%$ \\
Oita & $76 \%$ \\
Miyazaki & $567 \%$ \\
Kagoshima & $928 \%$ \\
Okinawa & $3014 \%$ \\
\hline Total Average & $316 \%$ \\
\hline
\end{tabular}


Table 9b (Continued)

Industry Average Errors and Regression $\mathbf{R}^{2}$ 's

\begin{tabular}{|lr|c|}
\hline Industry & Error & $\mathrm{R}^{2}$ \\
\hline Agriculture/Fishery & $32 \%$ & 0.798 \\
Mining & $115 \%$ & 0.366 \\
Construction & $9 \%$ & 0.928 \\
Processed Food & $35 \%$ & 0.605 \\
Textiles & $300 \%$ & 0.241 \\
Apparel & $79 \%$ & 0.223 \\
Lumber and Wood & $39 \%$ & 0.349 \\
Furniture & $94 \%$ & 0.404 \\
Paper \& Pulp & $131 \%$ & 0.274 \\
Publishing & $104 \%$ & 0.697 \\
Chemicals & $501 \%$ & 0.474 \\
Petroleum \& Coal & $2200 \%$ & 0.370 \\
Rubber & $355 \%$ & 0.405 \\
Leather \& Footwear & $525 \%$ & 0.362 \\
Ceramics \& Glass & $47 \%$ & 0.192 \\
Iron \& Steel & $347 \%$ & 0.523 \\
Non-Ferrous Metals & $852 \%$ & 0.419 \\
Metal Products & $73 \%$ & 0.547 \\
General Machinery & $316 \%$ & 0.606 \\
Electrical Machinery & $406 \%$ & 0.368 \\
Transport Machinery & $657 \%$ & 0.417 \\
Precision Instrument & $1652 \%$ & 0.171 \\
Other Manufacturing & $158 \%$ & 0.570 \\
Transportation/Communication & $21 \%$ & 0.866 \\
Electricity/Gas/Water & $36 \%$ & 0.472 \\
Wholesale/Retail & $30 \%$ & 0.784 \\
Finance/Insurance/Real Estate & $16 \%$ & 0.870 \\
Other Services & $23 \%$ & 0.817 \\
Public Administration & $11 \%$ & 0.872 \\
\hline Total Average & $316 \%$ & 0.517 \\
\hline
\end{tabular}


Table 10

Comparison of Models Using the Schwartz Criterion

\begin{tabular}{|l|c|c|}
\hline \multicolumn{1}{|c|}{ Model } & $\begin{array}{c}\text { Log- } \\
\text { Likelihood }\end{array}$ & $\begin{array}{c}\text { Schwartz } \\
\text { Criterion }\end{array}$ \\
\hline Three Factor Model & $-11,502$ & $-11,921$ \\
Five Factor Model & $-11,430$ & $-12,058$ \\
SevenFactor Model & $-11,367$ & $-12,205$ \\
\hline
\end{tabular}

The Schwartz criterion $=\log ($ likelihood $)-p / 2 * \log (n)$, where $p$ is the number of estimated parameters and $n$ is the number of observations. Higher values are preferred.

3-factor model: non-college-educated labor, college-educated labor, and capital

5-factor model: $\quad$ same as above, plus usable land and undeveloped mountain/forest land

7-factor model: capital, the 2 land variables, and 4 labor variables corresponding to the level of education (below high school, high school, two-year college, four-year college) 


\section{Table 11}

Average Prediction Error for Factor Endowments Using International Data $\left|\frac{B X}{V}-1\right|$

\section{Country Averages}

\begin{tabular}{|lr|}
\hline Argentina & $91 \%$ \\
Austria & $171 \%$ \\
Canada & $28 \%$ \\
Finland & $22 \%$ \\
Germany (West) & $333 \%$ \\
India & $72 \%$ \\
Indonesia & $61 \%$ \\
Ireland & $80 \%$ \\
Israel & $29 \%$ \\
Italy & $110 \%$ \\
Mexico & $56 \%$ \\
New Zealand & $115 \%$ \\
Norway & $59 \%$ \\
Philippines & $53 \%$ \\
Portugal & $42 \%$ \\
Singapore & $101 \%$ \\
Spain & $38 \%$ \\
Thailand & $51 \%$ \\
Turkey & $48 \%$ \\
U.S.A. & $67 \%$ \\
\hline Total Average & $81 \%$ \\
\hline
\end{tabular}

Factor Averages

\begin{tabular}{|l|c|c|c|c|}
\hline & Capital Stock & $\begin{array}{c}\text { Non-College- } \\
\text { Educated Labor }\end{array}$ & $\begin{array}{c}\text { College } \\
\text { Graduates }\end{array}$ & All Factors \\
\hline All Countries & $54 \%$ & $71 \%$ & $119 \%$ & $81 \%$ \\
\hline
\end{tabular}


Table 12

Correlation Between Endowment Deviations and Factor Intensity of Production for International Data

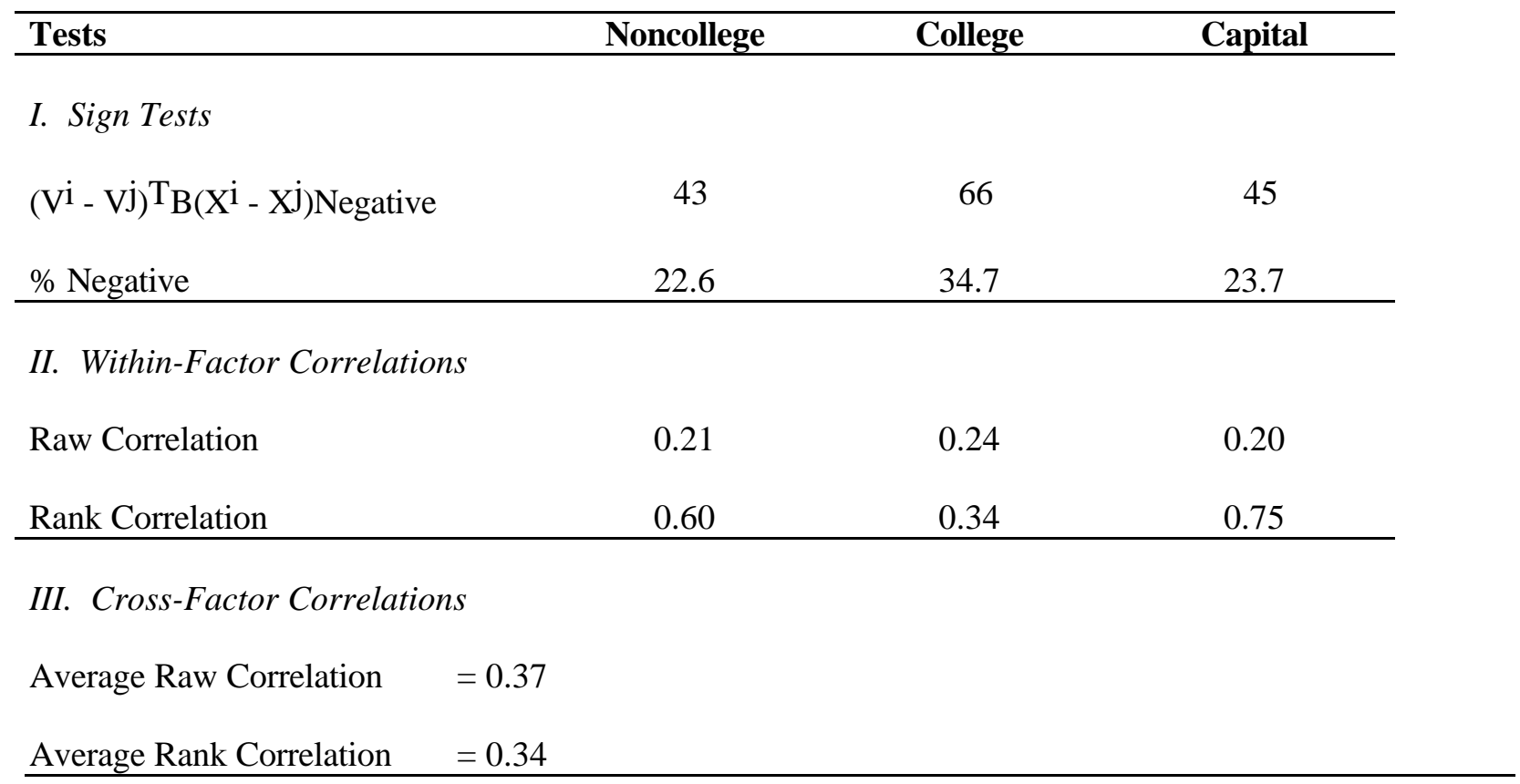


Table 13

Average Prediction Error for Outputs and Regression $\mathbf{R}^{2}$ 's Using International Data (5 Factors, 1/SQRT(GDP) Weighting)

\section{Country Average Errors}

\begin{tabular}{|lr|}
\hline Australia & $73 \%$ \\
Austria & $26 \%$ \\
Belgium/Luxembourg & $44 \%$ \\
Canada & $31 \%$ \\
Denmark & $64 \%$ \\
Finland & $42 \%$ \\
France & $43 \%$ \\
Germany (West) & $45 \%$ \\
Great Britain & $20 \%$ \\
Greece & $66 \%$ \\
Ireland & $101 \%$ \\
Italy & $48 \%$ \\
Japan & $14 \%$ \\
Netherlands & $86 \%$ \\
New Zealand & $76 \%$ \\
Norway & $114 \%$ \\
Portugal & $97 \%$ \\
Spain & $41 \%$ \\
Sweden & $50 \%$ \\
Turkey & $308 \%$ \\
United States & $7 \%$ \\
Yugoslavia & $69 \%$ \\
\hline Total Average & $67 \%$ \\
\hline
\end{tabular}

Industry Average Errors and Regression $R^{2}$ 's

\begin{tabular}{|l|r|c|}
\hline Industry & Error & $\mathrm{R}^{2}$ \\
\hline Processed Food & $25 \%$ & 0.911 \\
Textiles & $43 \%$ & 0.876 \\
Apparel & $50 \%$ & 0.918 \\
Lumber and Wood & $50 \%$ & 0.744 \\
Furniture & $34 \%$ & 0.763 \\
Paper \& Pulp & $98 \%$ & 0.720 \\
Publishing & $42 \%$ & 0.869 \\
Chemicals & $36 \%$ & 0.960 \\
Petroleum \& Coal & $111 \%$ & 0.853 \\
Rubber & $50 \%$ & 0.896 \\
Leather \& Footwear & $78 \%$ & 0.610 \\
Ceramics \& Glass & $25 \%$ & 0.896 \\
Iron \& Steel & $50 \%$ & 0.881 \\
Non-Ferrous Metals & $49 \%$ & 0.942 \\
Metal Products & $35 \%$ & 0.915 \\
General Machinery & $54 \%$ & 0.954 \\
Electrical Machinery & $64 \%$ & 0.873 \\
Transport Machinery & $53 \%$ & 0.960 \\
Precision Instrument & $317 \%$ & 0.863
\end{tabular}




\begin{tabular}{|l|l|l|}
\hline Total Average & $67 \%$ & 0.863 \\
\hline
\end{tabular}




\section{DATA APPENDIX}

\section{PREFECTURAL ENDOWMENTS}

The numbers of workers by educational attainment were entered by prefecture directly from the Employment Status Survey of 1987 (Shugyo Kozo Kihon Chosa Hokoku). The capital stocks were imputed from prefectural investment data. Japan's yearly Prefectural Accounts (Kenmin Keizai Keisan Nempo) give investment flows for each prefecture from 1975 to 1985. These flows were used to impute capital stock levels for each prefecture in 1985, using capital goods price deflators from the National Accounts (Kokumin Keizai Keisan Nempo) and a rate of depreciation of 0.133 (This was the same rate of depreciation used by Bowen, Leamer, and Sveikauskas (1987)). Each year's flow was deflated using a capital deflator from the National Accounts.

\section{WORLD ENDOWMENTS}

World endowments of capital stocks were calculated using investment flows between 1975 and 1985 from the Summers and Heston (1988) data set. As in the prefectural data, we used a perpetual inventory method (with a depreciation rate of 0.133 ) and capital price deflators from Summers and Heston to calculate capital stocks. In order to maintain compatibility with Davis, Weinstein et al. (1997) world endowments of labor force by educational level were taken from the UNESCO Statistical Yearbook. Once again we had a scaling problem arising from the fact that the Summers and Heston numbers and the UNESCO numbers did not match the Japanese numbers exactly. We therefore scaled each country's capital stock by the ratio of our calculated Japanese capital stock to the Summers and Heston value for the Japanese capital stock. The imputed international labor endowments were similarly scaled by the proportional difference between the UNESCO numbers and the actual Japanese endowments. For our regressions of international output on endowments, land data was taken from Leamer (1984) and mineral output data from Davis and Weinstein (1996). Education data was taken from Reeve (1998). Reeve assembled a broad cross-section of education endowment data by using Barro and Lee data on shares of the population over 25 with various levels of education (from the UNESCO source above) and multiplying it by labor force numbers from Summers and Heston.

\section{Prefectural Production}

The gross output of 20 manufacturing sectors in each prefecture was taken from the Japanese Census of Manufactures for 1985. The gross output of 9 non-manufacturing sectors in each prefecture was taken from the Prefectural Accounts for 1985. Finally, these totals were scaled so that the 47-prefectural total for each sector exactly matched the total Japanese output as reported in the 1985 Input-Output Table of Japan. Thus, in effect, the data from the Census of Manufactures and from the Prefectural Accounts was used in order to distribute total Japanese output for each sector across the 47 prefectures as accurately as possible.

\section{WORLD PRODUCTION}

Data on international levels of production used in tests of BX $=\mathrm{V}$ came from the United Nations' National Accounts Statistics: Main Aggregates and Detailed Tables, 1985. These numbers differed slightly from the numbers reported in the Japanese IO table, so the output of each sector in every country's output was scaled by the factor necessary to make the international data on Japan match the IO data. Where countries only reported value added rather than gross output, we scaled the value added by the ratio of gross output to value added in that sector in Japan. The 
data were then converted to Yen using exchange rate data from the IMF's International Financial Statistics.

Because the COMTAP database provides more detailed sales numbers than the UN, we used COMTAP data for our regressions Data on OECD production was taken from the COMTAP Database. This data was graciously provided by James Harrigan and is available in Feenstra et al. (1997)

\section{TECHNOLOGY}

Each element of the $3 \times 29$ technology matrix B was calculated by dividing Japanese total output for the 29 sectors into the number of each factor present in each sector. Most of the data on college and non-college workers in each sector came from the 1988 Wage Census. There were some gaps in this data as follows: 1) There was no data for college and non-college workers for agriculture, forestry, and fisheries or for government. These numbers were taken from the 1987 Employment Status Survey. 2) There was also no data for the petroleum/coal and leather industries. Total employment for each of these sectors was taken from the 1985 Census of Manufactures. The number of college workers per unit output for each was then imputed by assuming that petroleum/coal has the same fraction of college workers as the chemicals sector and that leather has the same fraction as manufacturing overall. The capital stocks in each of the 29 sectors were imputed from investment numbers, using the Annual Report of the Corporation Survey for non-manufacturing and the Census of Manufactures for manufacturing. 


\section{RESULTS APPENDIX}

The following tables give regression outputs for the indicated specifications.

Table A1: Prefectural Data, 5-Factor Model

Table A2: Prefectural Data, 7-Factor Model

Table A3: International Data, 5-Factor Model 
Table A1: Prefectural Data, 5-Factor Model

(Standard Errors in Parentheses, Constant Not Reported)

\begin{tabular}{lcccccc}
\multicolumn{1}{c}{$\begin{array}{c}\text { Dependent } \\
\text { Variable }\end{array}$} & $\begin{array}{c}\text { Non- } \\
\text { College }\end{array}$ & College & Capital & $\begin{array}{c}\text { Usable } \\
\text { Land }\end{array}$ & $\begin{array}{c}\text { Mountain } \\
\text { or Forest }\end{array}$ & $\mathrm{R}^{2}$ \\
Agriculture/Fishery & 0.303 & -0.364 & -0.262 & 110.6 & -2.50 & 0.780 \\
& $(0.110)$ & $(0.252)$ & $(0.029)$ & $(18.811)$ & $(16.622)$ & \\
Mining & -0.043 & -0.049 & 0.016 & 7.08 & -0.556 & 0.172 \\
& $(0.025)$ & $(0.058)$ & $(0.007)$ & $(4.31)$ & $(3.81)$ & \\
Construction & 0.132 & 0.584 & 0.113 & 66.2 & -5.95 & 0.910 \\
& $(0.116)$ & $(0.267)$ & $(0.030)$ & $(19.9)$ & $(17.6)$ & \\
Processed Food & 0.651 & -0.221 & -0.007 & 45.8 & -27.4 & 0.584 \\
& $(0.203)$ & $(0.465)$ & $(0.053)$ & $(34.6)$ & $(0.606)$ & \\
Textiles & 0.107 & -1.10 & 0.092 & -92.3 & 3.62 & 0.207 \\
& $(0.184)$ & $(0.421)$ & $(0.048)$ & $(31.4)$ & $(27.7)$ & \\
Apparel & 0.074 & -0.131 & 0.004 & -21.0 & 11.3 & 0.172 \\
& $(0.042)$ & $(0.097)$ & $(0.011)$ & $(7.20)$ & $(6.36)$ & \\
Lumber and Wood & 0.031 & -0.155 & 0.012 & -0.832 & 14.21 & 0.346 \\
& $(0.041)$ & $(0.094)$ & $(0.011)$ & $(7.03)$ & $(6.21)$ & \\
Furniture & 0.057 & -0.118 & 0.006 & -11.6 & 1.47 & 0.365 \\
& $(0.026)$ & $(0.058)$ & $(0.007)$ & $(4.36)$ & $(3.85)$ & \\
Paper \& Pulp & 0.291 & -0.142 & -0.020 & -16.8 & 13.9 & 0.252 \\
& $(0.115)$ & $(0.264)$ & $(0.030)$ & $(19.6)$ & $(17.4)$ & \\
Publishing & -0.461 & 0.497 & 0.106 & -14.6 & -2.95 & 0.637 \\
& $(0.131)$ & $(0.300)$ & $(0.034)$ & $(22.3)$ & $(19.7)$ & \\
Chemicals & 0.601 & 0.160 & -0.021 & -128 & 56.6 & 0.363 \\
& $(0.330)$ & $(0.755)$ & $(0.086)$ & $(56.2)$ & $(49.7)$ & \\
Petroleum \& Coal & -0.122 & 0.948 & 0.014 & -25.1 & 54.0 & 0.142 \\
& $(0.386)$ & $(0.882)$ & $(0.100)$ & $(65.7)$ & $(58.0)$ & \\
Rubber & 0.073 & -0.123 & 0.010 & -16.9 & -1.25 & 0.375 \\
& $(0.045)$ & $(0.102)$ & $(0.012)$ & $(7.59)$ & $(6.70)$ & \\
Leather \& Footwear & -0.006 & 0.100 & -0.0007 & -0.163 & -5.09 & 0.361 \\
& $(0.021)$ & $(0.048)$ & $(0.005)$ & $(3.55)$ & $(3.14)$ & \\
& & & & & &
\end{tabular}


Table A1 (Continued)

\begin{tabular}{|c|c|c|c|c|c|c|}
\hline $\begin{array}{l}\text { Dependent } \\
\text { Variable }\end{array}$ & $\begin{array}{l}\text { Non- } \\
\text { College }\end{array}$ & College & Capital & $\begin{array}{l}\text { Usable } \\
\text { Land }\end{array}$ & $\begin{array}{l}\text { Mountain } \\
\text { or Forest }\end{array}$ & $\mathrm{R}^{2}$ \\
\hline Ceramics \& Glass & $\begin{array}{c}0.201 \\
(0.114)\end{array}$ & $\begin{array}{l}-0.340 \\
(0.261)\end{array}$ & $\begin{array}{c}0.017 \\
(0.030)\end{array}$ & $\begin{array}{l}-36.7 \\
(19.5)\end{array}$ & $\begin{array}{c}17.5 \\
(17.2)\end{array}$ & 0.173 \\
\hline Iron \& Steel & $\begin{array}{c}0.220 \\
(0.326)\end{array}$ & $\begin{array}{c}-0.441 \\
(0.744)\end{array}$ & $\begin{array}{c}0.087 \\
(0.085)\end{array}$ & $\begin{array}{c}-107 \\
(55.5)\end{array}$ & $\begin{array}{c}33.6 \\
(49.0)\end{array}$ & 0.329 \\
\hline Non-Ferrous Metals & $\begin{array}{c}0.241 \\
(0.070)\end{array}$ & $\begin{array}{l}-0.136 \\
(0.161)\end{array}$ & $\begin{array}{l}-0.014 \\
(0.018)\end{array}$ & $\begin{array}{l}-13.4 \\
(12.0)\end{array}$ & $\begin{array}{l}-15.4 \\
(10.6)\end{array}$ & 0.394 \\
\hline Metal Products & $\begin{array}{c}0.419 \\
(0.157)\end{array}$ & $\begin{array}{l}-0.315 \\
(0.358)\end{array}$ & $\begin{array}{c}0.014 \\
(0.041)\end{array}$ & $\begin{array}{l}-40.4 \\
(26.7)\end{array}$ & $\begin{array}{l}-44.3 \\
(23.6)\end{array}$ & 0.545 \\
\hline General Machinery & $\begin{array}{c}0.951 \\
(0.297)\end{array}$ & $\begin{array}{c}-0.573 \\
(0.678)\end{array}$ & $\begin{array}{c}0.014 \\
(0.077)\end{array}$ & $\begin{array}{c}-157 \\
(50.5)\end{array}$ & $\begin{array}{l}-14.9 \\
(44.6)\end{array}$ & 0.605 \\
\hline Electrical Machinery & $\begin{array}{c}1.30 \\
(0.505)\end{array}$ & $\begin{array}{c}0.730 \\
(0.153)\end{array}$ & $\begin{array}{l}-0.131 \\
(0.131)\end{array}$ & $\begin{array}{l}-72.3 \\
(85.9)\end{array}$ & $\begin{array}{l}-36.3 \\
(75.9)\end{array}$ & 0.364 \\
\hline Transport Machinery & $\begin{array}{c}1.32 \\
(0.788)\end{array}$ & $\begin{array}{l}-3.36 \\
(1.80)\end{array}$ & $\begin{array}{c}0.222 \\
(0.205)\end{array}$ & $\begin{array}{l}-385 \\
(134)\end{array}$ & $\begin{array}{l}51.0 \\
(118)\end{array}$ & 0.405 \\
\hline Precision Instrument & $\begin{array}{c}0.056 \\
(0.100)\end{array}$ & $\begin{array}{c}0.044 \\
(0.228)\end{array}$ & $\begin{array}{c}0.004 \\
(0.026)\end{array}$ & $\begin{array}{l}-4.85 \\
(16.9)\end{array}$ & $\begin{array}{l}-2.70 \\
(15.0)\end{array}$ & 0.146 \\
\hline Other Manufacturing & $\begin{array}{c}0.589 \\
(0.141)\end{array}$ & $\begin{array}{l}-0.069 \\
(0.322)\end{array}$ & $\begin{array}{l}-0.047 \\
(0.037)\end{array}$ & $\begin{array}{l}-44.8 \\
(24.0)\end{array}$ & $\begin{array}{l}-25.6 \\
(21.2)\end{array}$ & 0.553 \\
\hline $\begin{array}{l}\text { Transportation } \\
\text { \&Communication }\end{array}$ & $\begin{array}{l}-0.685 \\
(0.144)\end{array}$ & $\begin{array}{c}0.674 \\
(0.331)\end{array}$ & $\begin{array}{c}0.225 \\
(0.038)\end{array}$ & $\begin{array}{l}-35.2 \\
(24.7)\end{array}$ & $\begin{array}{l}21.5 \\
(21.8)\end{array}$ & 0.859 \\
\hline Electricity/Gas/Water & $\begin{array}{l}-0.016 \\
(0.165)\end{array}$ & $\begin{array}{l}-0.590 \\
(0.377)\end{array}$ & $\begin{array}{c}0.113 \\
(0.043)\end{array}$ & $\begin{array}{l}-44.4 \\
(28.1)\end{array}$ & $\begin{array}{c}3.39 \\
(24.8)\end{array}$ & 0.389 \\
\hline Wholesale/Retail & $\begin{array}{c}-1.12 \\
(0.396)\end{array}$ & $\begin{array}{c}-0.677 \\
(0.906)\end{array}$ & $\begin{array}{c}0.553 \\
(0.103)\end{array}$ & $\begin{array}{c}-153 \\
(67.5)\end{array}$ & $\begin{array}{c}1.91 \\
(59.6)\end{array}$ & 0.767 \\
\hline $\begin{array}{l}\text { Finance/Insurance/Real } \\
\text { Estate }\end{array}$ & $\begin{array}{l}-0.623 \\
(0.239)\end{array}$ & $\begin{array}{c}1.77 \\
(0.546)\end{array}$ & $\begin{array}{c}0.240 \\
(0.062)\end{array}$ & $\begin{array}{l}-42.7 \\
(40.7)\end{array}$ & $\begin{array}{c}21.2 \\
(35.9)\end{array}$ & 0.860 \\
\hline Other Services & $\begin{array}{c}-2.06 \\
(0.471)\end{array}$ & $\begin{array}{c}1.65 \\
(1.08)\end{array}$ & $\begin{array}{c}0.639 \\
(0.123)\end{array}$ & $\begin{array}{l}-59.5 \\
(80.3)\end{array}$ & $\begin{array}{c}21.9 \\
(71.0)\end{array}$ & 0.791 \\
\hline Public Administration & $\begin{array}{l}-0.131 \\
(0.088)\end{array}$ & $\begin{array}{c}0.351 \\
(0.200)\end{array}$ & $\begin{array}{c}0.103 \\
(0.023)\end{array}$ & $\begin{array}{c}45.6 \\
(14.9)\end{array}$ & $\begin{array}{c}3.49 \\
(13.2)\end{array}$ & 0.852 \\
\hline
\end{tabular}


Table A2: Prefectural Data 7-Factor Model

\section{(Standard Errors in Parentheses, Constant Not Reported)}

\begin{tabular}{|c|c|c|c|c|c|c|c|c|}
\hline ependent Variable & $\begin{array}{c}\text { Less } \\
\text { Than } \\
\text { HS }\end{array}$ & $\begin{array}{l}\text { High } \\
\text { School }\end{array}$ & $\begin{array}{l}2 \text {-year } \\
\text { College }\end{array}$ & College & Capital & $\begin{array}{l}\text { Land in } \\
\text { Use }\end{array}$ & $\begin{array}{l}\text { Forest } \\
\text { or } \\
\text { Mount. }\end{array}$ & $\mathrm{R}^{2}$ \\
\hline griculture/Fishery & $\begin{array}{c}0.563 \\
(0.247)\end{array}$ & $\begin{array}{l}-0.165 \\
(0.261)\end{array}$ & $\begin{array}{l}-2.99 \\
(1.87)\end{array}$ & $\begin{array}{c}0.791 \\
(0.703)\end{array}$ & $\begin{array}{c}-0.018 \\
(0.029)\end{array}$ & $\begin{array}{c}115 \\
(18.7)\end{array}$ & $\begin{array}{l}-7.08 \\
(16.8)\end{array}$ & 0.798 \\
\hline Mining & $\begin{array}{c}0.004 \\
(0.058)\end{array}$ & & $\begin{array}{c}0.161 \\
(0.442)\end{array}$ & & & $\begin{array}{c}6.77 \\
(4.42)\end{array}$ & & 0.366 \\
\hline onstruction & $\begin{array}{c}0.434 \\
(0.244)\end{array}$ & $\begin{array}{l}-0.400 \\
(0.258)\end{array}$ & $\begin{array}{c}5.80 \\
(1.85)\end{array}$ & & & $\begin{array}{c}57.8 \\
(18.5)\end{array}$ & & 0.928 \\
\hline ocessed F & $\begin{array}{c}0.439 \\
(0.463)\end{array}$ & $\begin{array}{c}1.08 \\
(0.488)\end{array}$ & & & & $\begin{array}{c}53.6 \\
(35.1)\end{array}$ & & 05 \\
\hline extiles & $\begin{array}{c}0.581 \\
(0.422)\end{array}$ & & & & & & & 0 \\
\hline pparel & & & & & & & & 0 \\
\hline Imber & $\begin{array}{c}-0.007 \\
(0.096)\end{array}$ & & & & & & & 0.349 \\
\hline Irnit & $\begin{array}{c}0.032 \\
(0.044)\end{array}$ & $\begin{array}{c}0.054 \\
(0.038)\end{array}$ & $\begin{array}{c}0.534 \\
(0.326)\end{array}$ & $\begin{array}{c}-0.363 \\
(0.116)\end{array}$ & & & & 0.404 \\
\hline per & $\begin{array}{c}0.242 \\
(0.266)\end{array}$ & $\begin{array}{c}0.245 \\
(0.280)\end{array}$ & $\begin{array}{c}1.94 \\
(2.01)\end{array}$ & $\begin{array}{l}-0.891 \\
(0.755)\end{array}$ & & & & \\
\hline ibli & $\begin{array}{l}-0.129 \\
(0.280)\end{array}$ & $\begin{array}{c}-1.02 \\
(0.295)\end{array}$ & $\begin{array}{c}5.76 \\
(2.12)\end{array}$ & & & & & \\
\hline Chen & $\begin{array}{c}-0.220 \\
(0.701)\end{array}$ & $\begin{array}{c}2.03 \\
(0.739)\end{array}$ & $\begin{array}{l}-13.5 \\
(5.31)\end{array}$ & & & & & 0.474 \\
\hline etroleum & $\begin{array}{c}-1.00 \\
(0.773)\end{array}$ & $\begin{array}{c}1.68 \\
(0.814)\end{array}$ & $\begin{array}{l}-19.8 \\
(5.85)\end{array}$ & & & $\begin{array}{c}8.58 \\
(58.5)\end{array}$ & $\begin{array}{c}69.1 \\
(52.4)\end{array}$ & 0.370 \\
\hline Rubber & $\begin{array}{c}-0.007 \\
(0.102)\end{array}$ & $\begin{array}{c}0.182 \\
(0.107)\end{array}$ & $\begin{array}{c}-1.05 \\
(0.770)\end{array}$ & $\begin{array}{c}0.117 \\
(0.289)\end{array}$ & $\begin{array}{c}0.010 \\
(0.012)\end{array}$ & & & 0.405 \\
\hline Leather \& I & $\begin{array}{c}0.0002 \\
(0.049)\end{array}$ & $\begin{array}{c}-0.859 \\
(0.051)\end{array}$ & $\begin{array}{c}0.011 \\
(0.369)\end{array}$ & $\begin{array}{c}0.137 \\
(0.138)\end{array}$ & & & & 0.362 \\
\hline eramics \& Glass & $\begin{array}{c}0.338 \\
(0.264)\end{array}$ & $\begin{array}{c}0.133 \\
(0.278)\end{array}$ & & & & & $\begin{array}{c}15.1 \\
(17.9)\end{array}$ & 0.192 \\
\hline Iron \& Stee & $\begin{array}{c}-1.02 \\
(0.642)\end{array}$ & $\begin{array}{c}2.18 \\
(0.676)\end{array}$ & & & & & $\begin{array}{c}55.0 \\
(43.6)\end{array}$ & 15 \\
\hline on-Ferrous Metal & $\begin{array}{c}0.176 \\
(0.161)\end{array}$ & $\begin{array}{c}0.370 \\
(0.170)\end{array}$ & $\begin{array}{l}-1.59 \\
(1.22)\end{array}$ & $\begin{array}{c}0.283 \\
(0.458)\end{array}$ & & & $\begin{array}{l}-14.3 \\
(10.9)\end{array}$ & 0.419 \\
\hline Metal Products & $\begin{array}{c}0.364 \\
(0.366)\end{array}$ & $\begin{array}{c}0.433 \\
(0.385)\end{array}$ & $\begin{array}{l}0.588 \\
(2.77)\end{array}$ & $\begin{array}{l}-0.676 \\
(1.04)\end{array}$ & $\begin{array}{c}-0.012 \\
(0.042)\end{array}$ & $\begin{array}{l}-41.9 \\
(27.7)\end{array}$ & $\begin{array}{l}-43.3 \\
(24.8)\end{array}$ & 0.547 \\
\hline
\end{tabular}


Table A2 (Continued)

\begin{tabular}{|c|c|c|c|c|c|c|c|c|}
\hline pen & $\begin{array}{c}\text { Less } \\
\text { Than } \\
\text { HS }\end{array}$ & $\begin{array}{l}\text { High } \\
\text { School }\end{array}$ & $\begin{array}{l}\text { year } \\
\text { llege }\end{array}$ & ge & tal & $\begin{array}{l}\text { and in } \\
\text { Use }\end{array}$ & $\begin{array}{l}\text { Forest } \\
\text { or } \\
\text { Mount. }\end{array}$ & $\mathrm{R}^{2}$ \\
\hline eneral Machinery & & $\begin{array}{c}0.856 \\
(0.730)\end{array}$ & & & & $\begin{array}{c}-159 \\
(52.4)\end{array}$ & & 0.60 \\
\hline ectrical Machinery & & & & & & & & \\
\hline ar & $\begin{array}{c}2.77 \\
(1.82)\end{array}$ & & & & & & & 0.417 \\
\hline 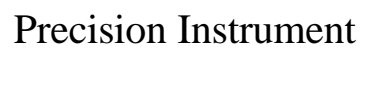 & $\begin{array}{c}-0.76 \\
(0.323)\end{array}$ & & & & & & & \\
\hline th & $\begin{array}{r}0.71 \\
(0.32\end{array}$ & & & & & & & \\
\hline 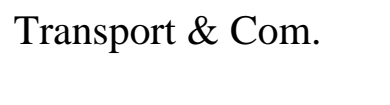 & $\begin{array}{c}-0.2\} \\
(0.3\end{array}$ & & & & & & $\begin{array}{c}14.5 \\
(22.4)\end{array}$ & 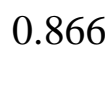 \\
\hline ect1 & 0. & & $\begin{array}{c}-5.93 \\
(2.716)\end{array}$ & & & & & \\
\hline ho & -1 . & & & & & & & 0.184 \\
\hline nan & & $\begin{array}{l}-1 \\
(0 .\end{array}$ & $\begin{array}{r}7 . \\
(4 .\end{array}$ & & & & & 0.8 \\
\hline her Service & & & & & & & & 0.8 \\
\hline blic & $\begin{array}{c}-0.003 \\
(0.190)\end{array}$ & $\begin{array}{c}-0.413 \\
(0.200)\end{array}$ & $\begin{array}{c}3.79 \\
(1.44)\end{array}$ & $\begin{array}{l}-0.663 \\
(0.541)\end{array}$ & $\begin{array}{c}0.010 \\
(0.022)\end{array}$ & $\begin{array}{c}40.1 \\
(14.4)\end{array}$ & $\begin{array}{c}1.30 \\
(12.9)\end{array}$ & 0.87 \\
\hline
\end{tabular}


Table A3: International Data 5-Factor Model (Standard Errors in Parentheses, Constant Not Reported)

\begin{tabular}{|c|c|c|c|c|c|c|}
\hline Dependent Variable & $\begin{array}{c}\text { Non- } \\
\text { College }\end{array}$ & College & Capital & Land & Fuel & $\mathrm{R}^{2}$ \\
\hline Processed Food & $\begin{array}{l}-352 \\
(262)\end{array}$ & $\begin{array}{c}687 \\
(1504)\end{array}$ & $\begin{array}{c}0.046 \\
(0.008)\end{array}$ & $\begin{array}{l}-132 \\
(121)\end{array}$ & $\begin{array}{c}40.4 \\
(19.1)\end{array}$ & 0.911 \\
\hline Textiles & $\begin{array}{l}-65.7 \\
(71.8)\end{array}$ & $\begin{array}{c}219 \\
(412)\end{array}$ & $\begin{array}{c}0.009 \\
(0.002)\end{array}$ & $\begin{array}{l}-7.42 \\
(33.2)\end{array}$ & $\begin{array}{l}-2.46 \\
(5.23)\end{array}$ & 0.876 \\
\hline Apparel & $\begin{array}{l}-46.3 \\
(31.7)\end{array}$ & $\begin{array}{c}198 \\
(182)\end{array}$ & $\begin{array}{c}0.005 \\
(0.001)\end{array}$ & $\begin{array}{c}4.58 \\
(14.6)\end{array}$ & $\begin{array}{c}2.03 \\
(2.31)\end{array}$ & 0.918 \\
\hline Lumber and Wood & $\begin{array}{c}-110 \\
(63.6)\end{array}$ & $\begin{array}{c}614 \\
(365)\end{array}$ & $\begin{array}{c}0.005 \\
(0.002)\end{array}$ & $\begin{array}{c}9.88 \\
(29.4)\end{array}$ & $\begin{array}{c}-0.204 \\
(4.63)\end{array}$ & 0.744 \\
\hline Furniture & $\begin{array}{c}11.3 \\
(32.9)\end{array}$ & $\begin{array}{c}277 \\
(189)\end{array}$ & $\begin{array}{c}0.003 \\
(0.001)\end{array}$ & $\begin{array}{c}-13.0 \\
(15.22)\end{array}$ & $\begin{array}{c}-0.970 \\
(2.40)\end{array}$ & 0.763 \\
\hline Paper \& Pulp & $\begin{array}{l}-248 \\
(154)\end{array}$ & $\begin{array}{l}1460 \\
(881)\end{array}$ & $\begin{array}{c}0.009 \\
(0.005)\end{array}$ & $\begin{array}{l}-20.3 \\
(70.9)\end{array}$ & $\begin{array}{c}5.28 \\
(11.2)\end{array}$ & 0.720 \\
\hline Publishing & $\begin{array}{l}-68.5 \\
(98.0)\end{array}$ & $\begin{array}{c}512 \\
(562)\end{array}$ & $\begin{array}{c}0.010 \\
(0.003)\end{array}$ & $\begin{array}{l}-43.4 \\
(45.3)\end{array}$ & $\begin{array}{c}16.2 \\
(7.13)\end{array}$ & 0.869 \\
\hline Chemicals & $\begin{array}{c}1.16 \\
(132)\end{array}$ & $\begin{array}{l}1894 \\
(759)\end{array}$ & $\begin{array}{c}0.025 \\
(0.004)\end{array}$ & $\begin{array}{l}-259 \\
(61.1)\end{array}$ & $\begin{array}{c}25.6 \\
(9.62)\end{array}$ & 0.959 \\
\hline Petroleum \& Coal & $\begin{array}{l}-221 \\
(311)\end{array}$ & $\begin{array}{c}1989 \\
(1783)\end{array}$ & $\begin{array}{c}0.025 \\
(0.010)\end{array}$ & $\begin{array}{l}-86.2 \\
(143)\end{array}$ & $\begin{array}{c}143 \\
(22.6)\end{array}$ & 0.853 \\
\hline Rubber & $\begin{array}{c}-128 \\
(80.7)\end{array}$ & $\begin{array}{c}245 \\
(463)\end{array}$ & $\begin{array}{c}0.014 \\
(0.002)\end{array}$ & $\begin{array}{l}-25.1 \\
(37.3)\end{array}$ & $\begin{array}{l}-1.56 \\
(5.88)\end{array}$ & 0.896 \\
\hline Leather \& Footwear & $\begin{array}{l}-5.87 \\
(27.0)\end{array}$ & $\begin{array}{l}-331 \\
(155)\end{array}$ & $\begin{array}{c}0.003 \\
(0.0008)\end{array}$ & $\begin{array}{c}11.9 \\
(12.5)\end{array}$ & $\begin{array}{r}-0.897 \\
(1.96)\end{array}$ & 0.610 \\
\hline Ceramics \& Glass & $\begin{array}{l}-61.3 \\
(62.0)\end{array}$ & $\begin{array}{l}-233 \\
(356)\end{array}$ & $\begin{array}{c}0.013 \\
(0.002)\end{array}$ & $\begin{array}{l}-9.67 \\
(28.6)\end{array}$ & $\begin{array}{l}-3.15 \\
(4.51)\end{array}$ & 0.895 \\
\hline Iron \& Steel & $\begin{array}{c}-12.30 \\
(120)\end{array}$ & $\begin{array}{l}-504 \\
(691)\end{array}$ & $\begin{array}{c}0.022 \\
(0.004)\end{array}$ & $\begin{array}{l}-61.5 \\
(55.6)\end{array}$ & $\begin{array}{l}-2.59 \\
(8.76)\end{array}$ & 0.881 \\
\hline Non-Ferrous Metals & $\begin{array}{c}-109 \\
(37.9)\end{array}$ & $\begin{array}{c}129 \\
(217)\end{array}$ & $\begin{array}{c}0.007 \\
(0.001)\end{array}$ & $\begin{array}{c}26.8 \\
(17.5)\end{array}$ & $\begin{array}{c}5.84 \\
(2.76)\end{array}$ & 0.942 \\
\hline Metal Products & $\begin{array}{l}-130 \\
(124)\end{array}$ & $\begin{array}{l}1977 \\
(712)\end{array}$ & $\begin{array}{c}0.015 \\
(0.004)\end{array}$ & $\begin{array}{l}-75.3 \\
(57.3)\end{array}$ & $\begin{array}{c}-0.001 \\
(9.03)\end{array}$ & 0.915 \\
\hline General Machinery & $\begin{array}{l}-79.5 \\
(144)\end{array}$ & $\begin{array}{l}2831 \\
(829)\end{array}$ & $\begin{array}{c}0.024 \\
(0.004)\end{array}$ & $\begin{array}{c}-241 \\
(66.7)\end{array}$ & $\begin{array}{c}7.72 \\
(10.51)\end{array}$ & 0.954 \\
\hline Electrical Machinery & $\begin{array}{l}-237 \\
(224)\end{array}$ & $\begin{array}{c}680 \\
(1284)\end{array}$ & $\begin{array}{c}0.033 \\
(0.007)\end{array}$ & $\begin{array}{l}-187 \\
(103)\end{array}$ & $\begin{array}{c}-3.81 \\
(16.3)\end{array}$ & 0.873 \\
\hline Transport Machinery & $\begin{array}{l}-271 \\
(176)\end{array}$ & $\begin{array}{c}3925 \\
(1008)\end{array}$ & $\begin{array}{c}0.033 \\
(0.005)\end{array}$ & $\begin{array}{c}-154 \\
(81.1)\end{array}$ & $\begin{array}{c}-10.6 \\
(12.79)\end{array}$ & 0.959 \\
\hline Precision Instruments & $\begin{array}{l}-29.6 \\
(64.7)\end{array}$ & $\begin{array}{c}908 \\
(371)\end{array}$ & $\begin{array}{c}0.005 \\
(0.002)\end{array}$ & $\begin{array}{l}-65.3 \\
(29.9)\end{array}$ & $\begin{array}{l}0.236 \\
(4.71)\end{array}$ & 0.863 \\
\hline
\end{tabular}

